\title{
miRNases: Novel peptide-oligonucleotide bioconjugates that silence miR-21 in lymphosarcoma cells
}

DOI:

10.1016/j.biomaterials.2017.01.018

\section{Document Version}

Accepted author manuscript

Link to publication record in Manchester Research Explorer

\section{Citation for published version (APA):}

Patutina, O. A., Bichenkova, E., Miroshnichenko, S. K., Mironova, N. L., Trivoluzzi, L., Burusco-Goni, K., Bryce, R., Vlassov, V. V., \& Zenkova, M. A. (2017). miRNases: Novel peptide-oligonucleotide bioconjugates that silence miR21 in lymphosarcoma cells. Biomaterials, 122, 163-178. https://doi.org/10.1016/j.biomaterials.2017.01.018

\section{Published in:}

Biomaterials

\section{Citing this paper}

Please note that where the full-text provided on Manchester Research Explorer is the Author Accepted Manuscript or Proof version this may differ from the final Published version. If citing, it is advised that you check and use the publisher's definitive version.

\section{General rights}

Copyright and moral rights for the publications made accessible in the Research Explorer are retained by the authors and/or other copyright owners and it is a condition of accessing publications that users recognise and abide by the legal requirements associated with these rights.

\section{Takedown policy}

If you believe that this document breaches copyright please refer to the University of Manchester's Takedown Procedures [http://man.ac.uk/04Y6Bo] or contact uml.scholarlycommunications@manchester.ac.uk providing relevant details, so we can investigate your claim.

\section{OPEN ACCESS}




\section{Accepted Manuscript}

miRNases: Novel peptide-oligonucleotide bioconjugates that silence miR-21 in lymphosarcoma cells

Olga A. Patutina, Elena V. Bichenkova, Svetlana K. Miroshnichenko, Nadezhda L. Mironova, Linda T. Trivoluzzi, Kepa K. Burusco, Richard A. Bryce, Valentin V. Vlassov, Marina A. Zenkova

PII: S0142-9612(17)30026-1

DOI: 10.1016/j.biomaterials.2017.01.018

Reference: $\quad$ JBMT 17901

To appear in: Biomaterials

Received Date: 21 November 2016

Revised Date: 9 January 2017

Accepted Date: 12 January 2017

Please cite this article as: Patutina OA, Bichenkova EV, Miroshnichenko SK, Mironova NL, Trivoluzzi LT, Burusco KK, Bryce RA, Vlassov VV, Zenkova MA, miRNases: Novel peptide-oligonucleotide bioconjugates that silence miR-21 in lymphosarcoma cells, Biomaterials (2017), doi: 10.1016/ j.biomaterials.2017.01.018.

This is a PDF file of an unedited manuscript that has been accepted for publication. As a service to our customers we are providing this early version of the manuscript. The manuscript will undergo copyediting, typesetting, and review of the resulting proof before it is published in its final form. Please note that during the production process errors may be discovered which could affect the content, and all legal disclaimers that apply to the journal pertain. 
AntimiR

oligonucleotide

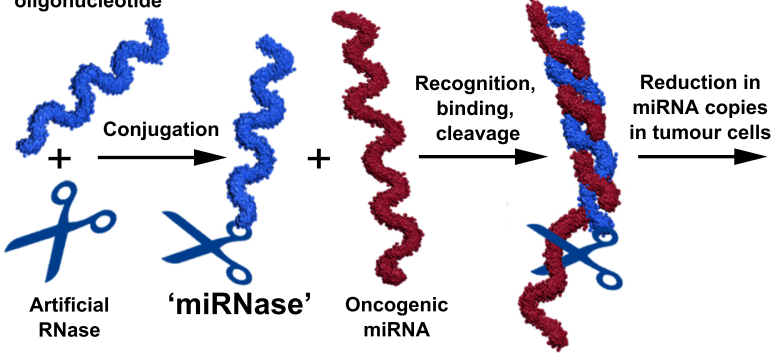

Inhibition of proliferation of tumour cells

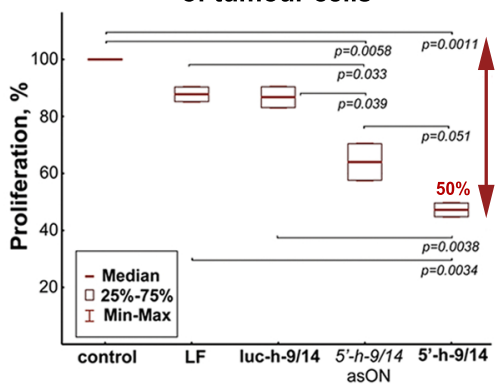




\title{
miRNases: novel peptide-oligonucleotide bioconjugates that silence miR-21 in
}

\section{lymphosarcoma cells}

Olga A. Patutina ${ }^{1}$, Elena V. Bichenkova ${ }^{2 *}$, Svetlana K. Miroshnichenko ${ }^{1}$, Nadezhda L. Mironova $^{1}$, Linda T. Trivoluzzi ${ }^{2}$, Kepa K. Burusco $^{2}$, Richard A. Bryce ${ }^{2}$, Valentin V. Vlassov ${ }^{1}$, Marina A. Zenkova ${ }^{1}$ *

${ }^{1}$ Laboratory of Nucleic Acids Biochemistry, Institute of Chemical Biology and Fundamental Medicine SB RAS, Lavrentiev ave., 8, Novosibirsk, 630090, Russia

${ }^{2}$ School of Health Sciences, Faculty of Biology, Medicine and Health, University of Manchester, Oxford Road, Manchester, UK, M13 9PT.

\begin{abstract}
MicroRNAs (miRNAs) are active regulators in malignant growth and constitute potential targets for anticancer therapy. Consequently, considerable effort has focused on identifying effective ways to modulate aberrant miRNA expression. Here we introduce and assess a novel type of chemically engineered biomaterial capable of cleaving specific miRNA sequences, i.e. miRNA-specific artificial ribonucleases (hereafter 'miRNase'). The miRNase template presented here consists of the catalytic peptide acetyl-[(LeuArg $\left.)_{2} \mathrm{Gly}\right]_{2}$ covalently attached to a miRNAtargeting oligonucleotide, which can be linear or hairpin. The peptide C-terminus is conjugated to an aminohexyl linker located at either the 3'- or 5'-end of the oligonucleotide. The cleavage efficacy, structural aspects of cleavage and biological relevance of a set of these designed miRNases was assayed with respect to highly oncogenic miR-21. Several miRNases demonstrated effective site-selective cleavage of miR-21 exclusively at G-X bonds. One of the most efficient miRNase was shown to specifically inhibit miR-21 in lymphosarcoma cells and lead to a reduction in their proliferative activity. This report provides the first experimental evidence that metallo-independent peptide-oligonucleotide chemical ribonucleases are able to effectively and selectively down-regulate oncogenic miRNA in tumour cells, thus suggesting their potential in development of novel therapeutics aimed at overcoming overexpression of disease-related miRNAs.
\end{abstract}

Keywords: peptide-oligonucleotide conjugates; RNA cleavage; antisense oligonucleotides; antimiRNA therapy; oncogenic miRNA; miR-21

* To whom correspondence should be addressed: Marina Zenkova, Laboratory of Nucleic Acids Biochemistry, Institute of Chemical Biology and Fundamental Medicine SB RAS, Lavrentiev ave., 8, Novosibirsk, 630090, Russia, Tel: +7(383)363-51-60; Fax: +7(383)363-51-53; e-mail: marzen@ niboch.nsc.ru; or Elena Bichenkova, School of Health Sciences, Faculty of Biology, Medicine and Health, University of Manchester, Oxford Road, Manchester, UK, M13 9PT, Tel: (+44) (0)161-2758359; Fax: (+44) (0)161-275-8360; e-mail: elena.v.bichenkova@manchester.ac.uk 


\section{Introduction}

In the last decade, non-coding RNAs and in particular miRNAs have been the focus of considerable research due to their association with a range of pathological conditions, from cancer to neurodegenerative, cardiovascular and autoimmune diseases [1-3]. MiRNAs represent a new class of regulatory molecule; they are 18-25 nucleotides in length and, through binding to specific mRNAs, are capable of post-transcriptional repression of gene expression, either by the RNA interference pathway or by translational arrest [4-6]. A large amount of evidence suggests that miRNAs exert control over fundamental physiological processes, both within the cell and at the level of the whole body [7, 8]. Disturbance in normal miRNA expression results in changes in the activity of target genes and is often associated with the initiation and progression of a wide spectrum of diseases, including oncology [9-12]. Tumor development is accompanied by an excess or deficiency of certain miRNAs compared to normal tissues. Increased expression of oncogenic miRNAs contributes to the development of neoplasia by suppression of tumorsuppressor genes, whereas a significant lack of tumor-suppressor miRNAs results in the overexpression of oncogenes [13, 14].

Modulation of activity of tumor-associated miRNAs is therefore of great scientific, biomedical and clinical interest. To date, a number of approaches have been developed for microRNA-based and miRNA-targeted therapies $[6,15]$. Restoring the level of deficient miRNA can be achieved by using miRNA mimics, representing synthetically prepared miRNAs [16, 17]; or viral constructs, encoding for miRNAs [18, 19]. Suppression of miRNA activity can be achieved using small-molecule inhibitors, acting at the transcriptional level [20]; via miRNA sponges, representing transcripts that contain multiple tandem-binding sites adsorbing deleterious miRNAs [21, 22]; by miR-mask oligonucleotides or target protectors, that are fully complementary to predicted miRNA binding sites in the $3^{\prime}$-UTR of the target mRNA [23-25]; and using antisense oligonucleotides, complementary to the target miRNA and inducing either its degradation or steric blockage [26, 27].

Numerous positive results have been achieved using strategies based on inhibition of oncogenic miRNAs. Indeed, the approaches based on miRNA suppression using miRNAsponges, representing molecular traps, were shown to restore the activity of tumour-suppressor genes. For example, miRNA sponges designed for modulation of miR-10b, miR-21, miR-155 and miR-221/222 mediate an impact on the activity of many protein targets, such as HOXD-10, PDCD4, Smad4, SRC3, Bcl-2 Bim, FOXO3a, PTEN and RhoA. Thus they provide inhibition of proliferation, activation of apoptosis and increase in the sensitivity of tumour cells to chemotherapy [28-30]. Suppression of oncogenic activity of miR-522 in a non-small cell lung 
cancer model was successfully achieved by the use of miRNA masking [31]. Antisense technology also has proven successful in blocking miRNA activity: synthetic oligonucleotides of different chemistries targeted to known oncogenic miRNAs, such as miR-17, miR-21, miR-155, and miR-221/222 promoted not only induction of apoptosis and inhibition of proliferation, but also tumour regression and metastasis suppression in vivo [32-38]. The drugs Miravirsen and Regulus RG-101, aimed at suppressing miRNA-122 for the treatment of hepatitis $\mathrm{C}$, have successfully progressed into clinical trials, and thus provide grounds to believe that, in the near future, effective antisense-based anti-miRNA therapies will be developed to combat oncopathology $[39,40]$.

Effective downregulation of miRNA levels in cells can be achieved by its selective, irreversible cleavage using agents that are capable of recognizing particular miRNA sequences. A direct approach to create such an artificial site-selective ribonuclease can be based on design of conjugates comprising of (i) antisense oligonucleotides (asON), which can form a complementary complex with a specific miRNA, and (ii) chemical moieties able to cleave phosphodiester bonds. These include metal complexes, imidazoles or cleaving peptides [41]. Over the last couple of decades, some progress has been achieved in the field of designing siteselective artificial ribonucleases [42-54]. It was shown that short peptides, containing either alternating leucine and arginine residues or imidazole-based catalytic groups, conjugated to antisense oligonucleotides targeting tRNA, were able to hydrolyze linkages adjacent to an oligonucleotide-binding site without involvement of exogenous species such as metal ions, enzymes or cofactors (e.g., RISC, RNase H) [42, 44, 45, 47, 50, 51]. Effective cleavage of complementary substrates was also demonstrated for tris(2-aminobenzimidazole) ribonuclease conjugated to PNA oligomers [49]. It is important to emphasize though that none of the above developments have been demonstrated against clinically relevant RNA sequences, and most of the studies in this area have been carried out so far using either short, linear RNA sequences or model RNAs (e.g. tRNAs).

Despite the fact that considerable success has been achieved in the area of development of site-selective, metal-free artificial ribonucleases, to date no studies have been reported demonstrating a successful downregulation of clinically significant miRNAs by such metalloindependent sequence-specific catalytic bioconjugates in eukaryotic cells. The key challenge of our research therefore was to assess whether such chemically engineered peptide-oligonucleotide conjugates (POCs) could potentially induce detectable downregulation of specific oncogenic miRNA in tumour cells, which is essential factor for future application in anticancer therapy. Here we report the development of miRNA-specific peptide-oligonucleotide conjugate ('miRNases') against highly oncogenic miR-21, and present the first experimental evidence of 
efficient, site-selective cleavage of this miRNA exclusively at G-X linkages by the most successful structural variants. Furthermore, we demonstrate here that one of the most efficient conjugates is capable of inducing specific inhibition of miR-21 in lymphosarcoma cells. This leads to reactivation of tumour-suppressor protein PDCD4, the direct target of mir-21, and subsequent reduction in proliferative activity of lymphosarcoma cells. To obtain structural insights into specific interactions between miRNases and miR-21 and to guide the future design of such conjugates, we carried out $1 \mu$ s molecular dynamics simulations of the hybridized complex between $\mathbf{5}$ '-h-6/14 conjugate and miR-21.

\section{Materials and methods}

\subsection{Instrumentation}

The details of chemicals, reagents and facilities used in this research have already been provided in our previous publications $[50,51]$. The software Topspin 3.2 was used to analyze the NMR data obtained. After electrophoresis the gels were analyzed using Molecular Imager FX (Bio-Rad, USA). PCR amplification was carried out using Bio-Rad iQ5 (Bio-Rad, USA).

\subsection{Oligonucleotides}

Oligodeoxyribonucleotides with an aminohexyl linker attached to either the 5'- or 3'terminal phosphate of the oligonucleotide sequence were synthesized in the Laboratory of Medicinal Chemistry, ICBFM, Russia, by the standard phosphoramidite protocol on an ASM800 synthesizer (Biosset, Russia) using solid support, nucleoside phosphoramidites and chemical phosphorylation reagent from Glenn Research (USA). Oligonucleotides were isolated by consecutive ion-exchange (Polysil SA-500 columns, Russia) and reverse-phase HPLC (LiChrosorb RP-18 columns, Merck, Germany) according to standard protocols.

\subsection{Peptide synthesis and purification}

Catalytic peptide Acetyl-(LeuArg) $)_{2}$-Gly-(LeuArg) $)_{2}-\mathrm{Gly}-\mathrm{COOH}$ was synthesized by manual solid-phase methodology on Fmoc-Gly-Wang resin using the Fmoc/t $\mathrm{Bu}$ strategy as described in [50]. Following completion of the peptide sequence, the N-terminus was acetylated by shaking with acetic anhydride $(10 \mathrm{mmol})$ and DIPEA $(10 \mathrm{mmol})$ in DMF $(10 \mathrm{~mL})$ for $30 \mathrm{~min}$, followed by resin washing with DMF $(2 \times 10 \mathrm{~mL}), \mathrm{DCM}(2 \times 10 \mathrm{~mL}$ and DMF $(2 \times 10 \mathrm{~mL})$. After acetylation of the sequence, the peptide was cleaved from the resin using the same protocol reported in [50]. Crude lyophilized peptide was solubilized in $30 \%$ acetic acid and purified using RP-HPLC as described earlier [50]. 
Acetyl-(LeuArg) $)_{2}$-Gly-(LeuArg)-Gly-COOH: Fractions collected at $33 \mathrm{~min}$ were combined and lyophilized to yield the TFA salt of the peptide as a fluffy white material. ESI-MS: $\mathrm{m} / \mathrm{z}=$ 626.4 for $[\mathrm{M}+\mathrm{H}+\mathrm{H}]^{2+}\left(\mathrm{MW}=1250.80\right.$ calcd. for $\left.\left[\mathrm{C}_{54} \mathrm{H}_{102} \mathrm{~N}_{22} \mathrm{O}_{12}\right]\right) .{ }^{1} \mathrm{H}$ NMR $\left(\mathrm{D}_{2} \mathrm{O}\right.$ with TSP $(0.1$ $\mu \mathrm{M}), 400 \mathrm{MHz}): \delta$ 0.83-0.97 (m, 24H, Leu-H $\left.{ }^{\delta}\right), 1.49-1.94\left(\mathrm{~m}, 28 \mathrm{H}, 8 \times \mathrm{Arg}-\mathrm{H}^{\beta}, 8 \times \mathrm{Arg}-\mathrm{H}^{\gamma}, 8 \times\right.$ Leu-H ${ }^{\beta}, 4 \times$ Leu-H $\left.{ }^{\gamma}\right), 2.04\left(\mathrm{~s}, 3 \mathrm{H}, \mathrm{CH}_{3}\right), 3.21\left(\mathrm{~m}, 8 \mathrm{H}, \mathrm{Arg}-\mathrm{H}^{\delta}\right), 3.82-4.41(\mathrm{~m}, 12 \mathrm{H}, 2 \times$ Gly-H , $8 \times$ Leu/Arg-H $\left.{ }^{\alpha}\right)($ see also Fig. S1).

\subsection{Synthesis of the conjugates}

Oligonucleotides containing an aminohexyl linker attached to either the 5'- or 3'-end of the oligonucleotide, $(50 \mathrm{nmol})$ in $\mathrm{H}_{2} \mathrm{O}(100 \mu \mathrm{L})$ were converted into cetyltrimethylammonium salt soluble in DMSO [50, 51].

Acetyl-(LeuArg) $)_{2}$-Gly-(LeuArg) $)_{2}-$ Gly-COOH (2.3 $\mu \mathrm{mol}$,) and 4-dimethylaminopyridine $(3.5 \mu \mathrm{mol})$ were dissolved in a minimal volume of anhydrous DMSO $(\approx 20 \mu \mathrm{L})$ before N,N'dicyclohexylcarbodiimide $(3.45 \mu \mathrm{mol})$ was added and vortexed. The resulting peptide solution was added directly to oligonucleotide solution and left at $60^{\circ} \mathrm{C}$ for $12 \mathrm{~h}$. The reaction product (along with the unreached starting oligonucleotide) was precipitated with $4 \% \mathrm{LiClO}_{4}$ in acetone using similar protocol described in $[50,51]$ followed RP-HPLC purification of the corresponding peptide-oligonucleotide conjugate [50].

\subsection{Conjugate purification}

Crude conjugates were dissolved in water and purified using RP-HPLC $(2.0 \mathrm{~mL} / \mathrm{min}$ flow rate, eluent $\mathrm{A}-0.05 \mathrm{M} \mathrm{LiClO}_{4}$, eluent $\mathrm{B}-0.05 \mathrm{M} \mathrm{LiClO}_{4}$ in $\mathrm{AcCN} ; 100 \%$ A for $5 \mathrm{~min}, 0 \% \mathrm{~B}$ to $50 \% \mathrm{~B}$ in $35 \mathrm{~min}$ ). Fractions containing conjugate were collected, combined and lyophilized. The excess of $\mathrm{LiClO}_{4}$ was removed by precipitation in $4 \% \mathrm{LiClO}_{4}$ in acetone (w/v) as reported earlier in $[50,51]$.

\subsection{Characterisation of conjugates}

The identity and purity of all peptide-oligonucleotide conjugates were confirmed by RPHPLC, ${ }^{1} \mathrm{H}-\mathrm{NMR}$ spectroscopy and mass spectrometry using matrix-assisted laser desorption ionisation (MALDI) spectroscopy (see below and Fig. S1). Conjugates were identified as monoor di-sodium adducts with experimental masses in agreement with theoretical calculations.

Conjugate 5'-16: MALDI-MS: $m / z=6192[\mathrm{M}+\mathrm{Na}]^{+}\left(\mathrm{MW}=6170\right.$ calcd for 5'-16). ${ }^{1} \mathrm{H}$ NMR $\left(\mathrm{D}_{2} \mathrm{O}, 400 \mathrm{MHz}\right): \delta$ 0.62-0.93 (m, 24H, Leu- $\left.{ }^{\delta}\right), 1.11-1.47\left(\mathrm{~m}, 12 \mathrm{H}, 6 \times \mathrm{CH}_{2}\right.$ (aminohexyl linker)), $1.49-2.18\left(\mathrm{~m}, 43 \mathrm{H}, 5 \times \mathrm{CH}_{3}\right.$ of $5 \times \mathrm{dT}, 8 \times \mathrm{Arg}-\mathrm{H}^{\beta}, 8 \times \mathrm{Arg}-\mathrm{H}^{\gamma}, 8 \times \mathrm{Leu}^{\mathrm{H}} \mathrm{H}^{\beta}, 4 \times$ Leu- $^{\gamma}$ ), 2.03 $\left(\mathrm{s}, 3 \mathrm{H}, \mathrm{CH}_{3}\right), 2.31-2.92(\mathrm{~m}, 32 \mathrm{H}, 16 \times \mathrm{H} 2$ ' and 16×H2', sugar ring protons), 3.05-3.14 (m, $8 \mathrm{H}$, $\left.8 \times \mathrm{Arg}-\mathrm{H}^{\delta}\right), 3.72-4.55(\mathrm{~m}, 60 \mathrm{H}, 16 \times \mathrm{H} 4$ ', $16 \times \mathrm{H} 5$ ' and $16 \times \mathrm{H} 5$ ', sugar ring protons, $4 \times \mathrm{Gly}-\mathrm{H}, 8 \times$ 
Leu/Arg- $\mathrm{H}^{\alpha}$ ), 5.52-6.53 (m, $19 \mathrm{H}, 16 \times \mathrm{H} 1$, MAgar ring protons, $3 \times \mathrm{H} 5$ of $\mathrm{dC}$ ), 7.25-8.28 (s or d, $21 \mathrm{H}, 21 \times \mathrm{Ar}-\mathrm{H}$ from $3 \times \mathrm{dG}(\mathrm{H} 8), 5 \times \mathrm{dA}(\mathrm{H} 8), 5 \times \mathrm{dA}(\mathrm{H} 2), 3 \times \mathrm{dC}(\mathrm{H} 6)$ and $5 \times \mathrm{dT}(\mathrm{H} 6))$. The H3' sugar ring proton regions (4.56-5.2 $\mathrm{ppm}$ ) were not analysed due to supression of residual water signal at 4.78ppm.

Conjugate 5'-h-6/14: MALDI-MS: $m / z=10554[\mathrm{M}+\mathrm{H}]^{+}(\mathrm{MW}=10553$ calcd. for 5'-h-6/14). ${ }^{1} \mathrm{H}$ NMR $\left(\mathrm{D}_{2} \mathrm{O}, 400 \mathrm{MHz}\right): \delta$ 0.62-0.93 (m, 24H, Leu- $\left.\mathrm{H}^{\delta}\right), 1.11-1.47\left(\mathrm{~m}, 12 \mathrm{H}, 6 \times \mathrm{CH}_{2}\right.$ (aminohexyl linker)), 1.49-2.18 (m, $46 \mathrm{H}, 6 \times \mathrm{CH}_{3}$ of $6 \times \mathrm{dT}, 8 \times \mathrm{Arg}-\mathrm{H}^{\beta}, 8 \times \mathrm{Arg}-\mathrm{H}^{\gamma}, 8 \times \mathrm{Leu}-\mathrm{H}^{\beta}$, $4 \times$ Leu- $^{\gamma}$ ), $2.03\left(\mathrm{~s}, 3 \mathrm{H}, \mathrm{CH}_{3}\right), 2.31-2.92(\mathrm{~m}, 60 \mathrm{H}, 30 \times \mathrm{H} 2$ ' and $30 \times \mathrm{H} 2$ ' sugar ring protons),

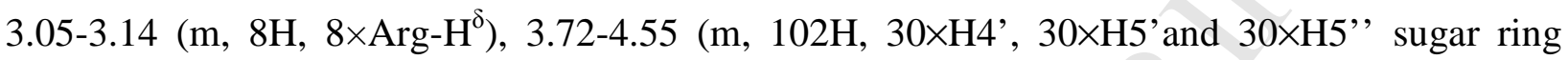
protons, $4 \times$ Gly-H, $\left.8 \times \mathrm{Leu} / \mathrm{Arg}-\mathrm{H}^{\alpha}\right), 5.52-6.53(\mathrm{~m}, 36 \mathrm{H}, 30 \times \mathrm{H} 1$ ' sugar ring protons, $6 \times \mathrm{H} 5$ of $\mathrm{dC}$ ), 7.22-8.31 (s or d, 40H, 40×Ar-H from $8 \times \mathrm{dG}(\mathrm{H} 8), 10 \times \mathrm{dA}(\mathrm{H} 8), 10 \times \mathrm{dA}(\mathrm{H} 2), 6 \times \mathrm{dC}(\mathrm{H} 6)$ and $6 \times \mathrm{dT}(\mathrm{H} 6))$. The H3' sugar ring proton regions (4.56-5.2 $\mathrm{ppm})$ were not analysed due to suppression of residual water signal at $4.78 \mathrm{ppm}$.

Conjugate 5'-h-9/14: MALDI-MS: $m / z=12424[\mathrm{M}+\mathrm{Na}]^{+}(\mathrm{MW}=12404$ calcd. for 5'-h-9/14). ${ }^{1} \mathrm{H}$ NMR $\left(\mathrm{D}_{2} \mathrm{O}, 400 \mathrm{MHz}\right): \delta 0.62-0.93\left(\mathrm{~m}, 24 \mathrm{H}, \quad\right.$ Leu- $\left.\mathrm{H}^{\delta}\right), 1.11-1.47\left(\mathrm{~m}, 12 \mathrm{H}, 6 \times \mathrm{CH}_{2}\right.$ (aminohexyl linker)), 1.49-2.18 (m, 52H, $8 \times \mathrm{CH}_{3}$ of $8 \times \mathrm{dT}, 8 \times \mathrm{Arg}-\mathrm{H}^{\beta}, 8 \times \mathrm{Arg}-\mathrm{H}^{\gamma}, 8 \times \mathrm{Leu}-\mathrm{H}^{\beta}$, $\left.4 \times \mathrm{Leu}^{\gamma} \mathrm{H}^{\gamma}\right), 2.03\left(\mathrm{~s}, 3 \mathrm{H}, \mathrm{CH}_{3}\right), 2.31-2.92(\mathrm{~m}, 72 \mathrm{H}, 36 \times \mathrm{H} 2$ ' and $36 \times \mathrm{H} 2$ '' sugar ring protons),

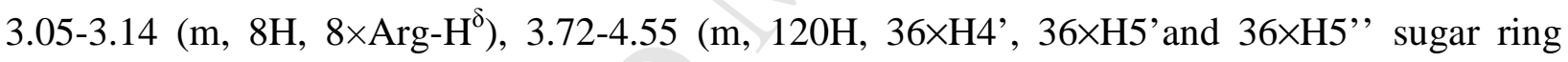
protons, $4 \times$ Gly-H, $\left.8 \times \mathrm{Leu} / \mathrm{Arg}-\mathrm{H}^{\alpha}\right), 5.52-6.53(\mathrm{~m}, 43 \mathrm{H}, 36 \times \mathrm{H} 1$ ' sugar ring protons, $7 \times \mathrm{H} 5$ of $\mathrm{dC}$ ), 7.22-8.31 (s or d, 48H, 48×Ar-H from $9 \times \mathrm{dG}(\mathrm{H} 8), 12 \times \mathrm{dA}(\mathrm{H} 8), 12 \times \mathrm{dA}(\mathrm{H} 2), 7 \times \mathrm{dC}(\mathrm{H} 6)$ and $8 \times \mathrm{dT}(\mathrm{H} 6))$. The H3' sugar ring proton regions (4.56-5.2 $\mathrm{ppm}$ ) were not analysed due to suppression of residual water signal at $4.78 \mathrm{ppm}$.

Conjugate 5'-h-6/16: MALDI-MS: $m / z=11165[\mathrm{M}+\mathrm{Na}]^{+}(\mathrm{MW}=11145$ calcd. for 5'-h-6/16). ${ }^{1} \mathrm{H}$ NMR $\left(\mathrm{D}_{2} \mathrm{O}, 400 \mathrm{MHz}\right): \delta$ 0.62-0.93 (m, 24H, Leu-H $\left.{ }^{\delta}\right), 1.11-1.47\left(\mathrm{~m}, 12 \mathrm{H}, 6 \times \mathrm{CH}_{2}\right.$ (aminohexyl linker)), 1.49-2.18 (m, 49H, $7 \times \mathrm{CH}_{3}$ of $7 \times \mathrm{dT}, 8 \times \mathrm{Arg}-\mathrm{H}^{\beta}, 8 \times \mathrm{Arg}-\mathrm{H}^{\gamma}, 8 \times \mathrm{Leu}-\mathrm{H}^{\beta}$,

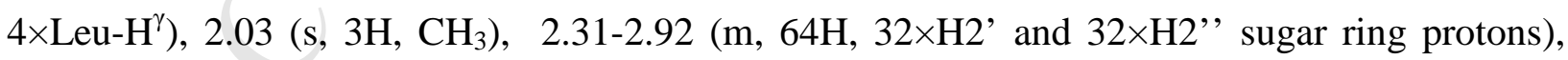
3.05-3.14 (m, 8H, 8×Arg- $\left.\mathrm{H}^{\delta}\right), 3.72-4.55(\mathrm{~m}, 108 \mathrm{H}, 32 \times \mathrm{H} 4$ ', $32 \times \mathrm{H} 5$ ' and $32 \times \mathrm{H} 5$ ' sugar ring protons, $4 \times$ Gly-H, $\left.8 \times \mathrm{Leu} / \mathrm{Arg}-\mathrm{H}^{\alpha}\right), 5.52-6.53(\mathrm{~m}, 39 \mathrm{H}, 32 \times \mathrm{H} 1$ ' sugar ring protons, $7 \times \mathrm{H} 5$ of $\mathrm{dC}$ ), 7.22-8.31 (s or d, 42H, 42×Ar-H from $8 \times \mathrm{dG}(\mathrm{H} 8), 10 \times \mathrm{dA}(\mathrm{H} 8), 10 \times \mathrm{dA}(\mathrm{H} 2), 7 \times \mathrm{dC}(\mathrm{H} 6)$ and $7 \times \mathrm{dT}(\mathrm{H} 6))$. The H3' sugar ring proton regions (4.56-5.2 $\mathrm{ppm}$ ) were not analysed due to suppression of residual water signal at $4.78 \mathrm{ppm}$.

Conjugate 5'-h-9/16: MALDI-MS: $m / z=12999[\mathrm{M}+\mathrm{H}]^{+}(\mathrm{MW}=\mathbf{1 2 9 9 7}$ calcd. for 5'-h-9/16). ${ }^{1} \mathrm{H}$ NMR $\left(\mathrm{D}_{2} \mathrm{O}, 400 \mathrm{MHz}\right): \delta 0.62-0.93\left(\mathrm{~m}, 24 \mathrm{H}\right.$, Leu- $\left.\mathrm{H}^{\delta}\right), 1.11-1.47\left(\mathrm{~m}, 12 \mathrm{H}, 6 \times \mathrm{CH}_{2}\right.$ 
(aminohexyl linker)), 1.49-2.18 (m, $55 \mathrm{H}, 9 \times \mathrm{CH}_{3}$ of $9 \times \mathrm{dT}, 8 \times \mathrm{Arg}-\mathrm{H}^{\beta}, 8 \times \mathrm{Arg}-\mathrm{H}^{\gamma}, 8 \times \mathrm{Leu}^{\mathrm{H}} \mathrm{H}^{\beta}$, $4 \times$ Leu- $^{\gamma}$ ), $2.03\left(\mathrm{~s}, 3 \mathrm{H}, \mathrm{CH}_{3}\right), 2.31-2.92(\mathrm{~m}, 76 \mathrm{H}, 38 \times \mathrm{H} 2$ ' and $38 \times \mathrm{H} 2$ ' sugar ring protons),

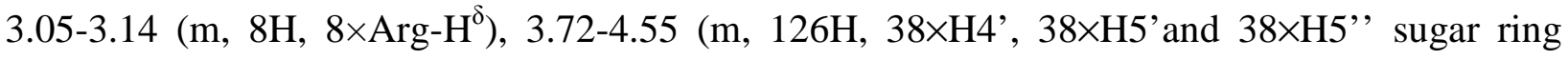
protons, $4 \times$ Gly-H, $\left.8 \times \mathrm{Leu} / \mathrm{Arg}-\mathrm{H}^{\alpha}\right), 5.52-6.53\left(\mathrm{~m}, 46 \mathrm{H}, 38 \times \mathrm{H} 1^{\prime}\right.$ sugar ring protons, $8 \times \mathrm{H} 5$ of $\mathrm{dC}$ ), 7.22-8.31 (s or d, 50H, 50×Ar-H from $9 \times \mathrm{dG}(\mathrm{H} 8), 12 \times \mathrm{dA}(\mathrm{H} 8), 12 \times \mathrm{dA}(\mathrm{H} 2), 8 \times \mathrm{dC}(\mathrm{H} 6)$ and 9xdT(H6)). The H3' sugar ring proton regions (4.56-5.2 $\mathrm{ppm}$ ) were not analysed due to suppression of residual water signal at $4.78 \mathrm{ppm}$.

Conjugate 5'-luc-h-9/14: MALDI-MS: $m / z=12429[\mathrm{M}+\mathrm{Na}]^{+}(\mathrm{MW}=12399$ calcd. for 5'-luch-9/14). ${ }^{1} \mathrm{H}$ NMR $\left(\mathrm{D}_{2} \mathrm{O}, 400 \mathrm{MHz}\right): \delta$ 0.62-0.93 (m, 24H, Leu-H $\left.{ }^{\delta}\right), 1.11-1.47\left(\mathrm{~m}, 12 \mathrm{H}, 6 \times \mathrm{CH}_{2}\right.$ (aminohexyl linker)), $1.49-2.18\left(\mathrm{~m}, 46 \mathrm{H}, 6 \times \mathrm{CH}_{3}\right.$ of $6 \times \mathrm{dT}, 8 \times \mathrm{Arg}-\mathrm{H}^{\beta}, 8 \times \mathrm{Arg}-\mathrm{H}^{\gamma}, 8 \times \mathrm{Leu}-\mathrm{H}^{\beta}$, $\left.4 \times \mathrm{Leu}^{\gamma} \mathrm{H}^{\gamma}\right), 2.03\left(\mathrm{~s}, 3 \mathrm{H}, \mathrm{CH}_{3}\right), 2.31-2.92(\mathrm{~m}, 72 \mathrm{H}, 36 \times \mathrm{H} 2$ ' and $36 \times \mathrm{H} 2$ ', sugar ring protons),

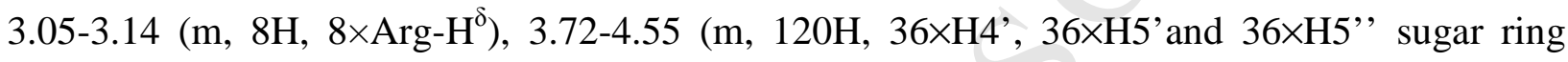
protons, $4 \times$ Gly-H, $\left.8 \times \mathrm{Leu} / \mathrm{Arg}-\mathrm{H}^{\alpha}\right), 5.52-6.53(\mathrm{~m}, 44 \mathrm{H}, 36 \times \mathrm{H} 1$ ' sugar ring protons, $8 \times \mathrm{H} 5$ of $\mathrm{dC}), 7.22-8.31$ (s or d, 49H, 48×Ar-H from $9 \times \mathrm{dG}(\mathrm{H} 8), 13 \times \mathrm{dA}(\mathrm{H} 8), 13 \times \mathrm{dA}(\mathrm{H} 2), 8 \times \mathrm{dC}(\mathrm{H} 6)$ and $6 \times \mathrm{dT}(\mathrm{H} 6))$. The H3' sugar ring proton regions (4.56-5.2 $\mathrm{ppm}$ ) were not analysed due to suppression of residual water signal at 4.78ppm.

\subsection{5'-RNA labelling}

MiR-21 5'-UAGCUUAUCAGACUGAUGUUGA-3' was synthesized by Dr. Maria I. Meschaninova (ICBFM SB RAS). 5'-end labelling using $\left[{ }^{32} \mathrm{P}\right] \mathrm{ATP}$ and T4 polynucleotide kinase (Thermo Scientific, USA) and isolation of $\left[{ }^{32} \mathrm{P}\right]-\mathrm{miR}-21$ was carried out according to procedure previously described in $[55,77]$.

\subsection{Gel-retardation assay}

The reaction mixture $(10 \mu \mathrm{l})$ containing $50 \mathrm{mM}$ Tris- $\mathrm{HCl}, \mathrm{pH} 7.0,0.2 \mathrm{M} \mathrm{KCl}$ and $1 \mathrm{mM}$ EDTA, $6000 \mathrm{cpm}$ (Cherenkov's counting) of $\left[{ }^{32} \mathrm{P}\right]-\mathrm{miR}-21,1 \mu \mathrm{M}$ unlabeled miR-21, antisense oligonucleotide (asON) at a concentration ranging from 0.5 to $100 \mu \mathrm{M}$ or conjugate at a concentration ranging from 1 to $50 \mu \mathrm{M}$, was incubated at $37^{\circ} \mathrm{C}$ for $1 \mathrm{~h}$ and quenched by adding of a loading buffer (20\% ficoll, $0.025 \%$ bromophenol blue, $0.025 \%$ xylene cyanol). The samples were loaded onto the running gel immediately after quenching of the reaction with an interval of $2 \mathrm{~min}$. Formation of the complex miR-21/asON or miR-21/conjugate was analyzed by electrophoresis in $12 \%$ native PAAG at $4{ }^{\circ} \mathrm{C}$. The gels were analyzed using Molecular Imager FX. The extent of binding of oligonucleotide to miR-21 was determined as a ratio of radioactivity measured in the complex to the total radioactivity applied onto the gel lane. 


\subsection{Ribonuclease activity assay}

The reaction mixture $(5 \mu \mathrm{l})$ contained $8000 \mathrm{cpm}$ (Cherenkov's counting) of [ $\left.{ }^{32} \mathrm{P}\right]-\mathrm{miR}-21$, $1 \mu \mathrm{M}$ unlabeled miR-21 and one of the conjugates at a concentration ranging from 1 to $50 \mu \mathrm{M}$, $50 \mathrm{mM}$ Tris- $\mathrm{HCl}, \mathrm{pH}$ 7.0, 0.2 $\mathrm{M} \mathrm{KCl}, 1 \mathrm{mM}$ EDTA. The mixture was incubated at $37^{\circ} \mathrm{C}$ (for various times) and quenched by precipitation of RNA with $2 \% \mathrm{LiClO}_{4}$ in acetone $(50 \mu \mathrm{l})$. RNA was collected by centrifugation and dissolved in loading buffer ( $8 \mathrm{M}$ urea, $0.025 \%$ bromophenol blue, $0.025 \%$ xylene cyanol). RNA cleavage products were analyzed in 18\% PAAG/8M urea using TBE (100 mM Tris-borate, $\mathrm{pH} 8.3,2$ mM EDTA) as running buffer. To identify cleavage sites, an imidazole and T1-ladders produced by partial RNA cleavage with $2 \mathrm{M}$ imidazole buffer ( $\mathrm{pH}$ 7.0) [56] and with RNase T1 [57], respectively, were run in parallel. To obtain quantitative data, gels were dried and analyzed using Molecular Imager FX. The total extent of RNA cleavage and the extent of RNA cleavage at each individual site were determined Quantity One software.

\subsection{Molecular Modelling}

Computational studies were performed with AMBER 15 (AMBER 14 and AMBERTOOLS 15 [58]) and MOE 2014.09 [59] molecular modelling packages. The initial 3D conformation of the complex between $\mathbf{5} \cdot \mathbf{- h}-\mathbf{6} / \mathbf{1 4}$ conjugate and miR-21 was generated via assembly of distinct components: the RNA-DNA hybrid double helix was modelled in the typeA form using the make-na online server (http://structure.usc.edu/make-na/server.htm). The hairpin structure was modelled from a NMR structure (PDB code 2 K71 [60]). An initial conformation of the peptide component was generated from homology using the SWISSMODEL online server [61]. Finally, the linker moiety joining the peptide to the oligonucleotide was modelled in and the components of the complex assembled via xLEaP. For molecular dynamics (MD) simulations, parameters were assigned to the complex from the ff14SBonlysc [62] and GAFF force fields [63]. The complex was solvated using the generalised Born implicit solvation model (igb=5) [64] with a Debye-Huckel salt concentration of 0.2 M. MD simulations employed SHAKE on all atoms involving hydrogen [65] a timestep of 2 fs and a cut-off of 999 $\AA$ for non-bonded interactions. Temperature was controlled using Langevin dynamics with a collision frequency of 2 ps. Subsequent to stepwise relaxation of solute constraints, the solvated complex was equilibrated for $10 \mathrm{~ns}$. A production run of $1 \mu \mathrm{s}$ was then acquired. Coordinates and energies were saved for analysis every ps. Simulations were performed using the pmemd.CUDA module of the AMBER 14 software package. 


\subsection{Transfection of tumour cells with conjugates}

Mouse lymphosarcoma cells RLS $_{40}$ were placed in a serum-free Iscove's Modified Dulbecco's Medium (IMDM) into 24-well plates immediately before transfection. The cells were incubated at $37^{\circ} \mathrm{C}$ in a humidified atmosphere with $5 \% \mathrm{CO}_{2}$ for $4 \mathrm{~h}$ with $1 \mu \mathrm{M}$ as $\mathrm{ON} 5^{\prime}-h-9 / 14$, or conjugate $\mathbf{5}$ '-h-9/14, or control conjugate luc-h-9/14 precomplexed with Lipofectamine 2000 (Invitrogen, USA) in an Opti-MEM medium. Then the medium was replaced with a culture medium containing $10 \%$ fetal bovine serum (FBS) and $1 \%$ antibiotic antimycotic solution (10 $000 \mu \mathrm{g} / \mathrm{ml}$ streptomycin, $10000 \mathrm{IU} / \mathrm{ml}$ penicillin, and $25 \mu \mathrm{g} / \mathrm{ml}$ amphotericin), and the cells were cultivated for $24-72 \mathrm{~h}$ under the same conditions. At time points 24,48 and $72 \mathrm{~h}$, total RNA was isolated from the cells using TRIzol Reagent (Invitrogen, USA) according to the manufacturer's protocol. At the time point $48 \mathrm{~h}$, cell lysates were prepared using RIPA buffer (Thermo Scientific, USA).

\subsection{2. $q P C R$}

Expression of miRNA in $\mathrm{RLS}_{40}$ cells was analyzed using stem-loop PCR technology [66, 67]. cDNA synthesis was carried out using SuperScript III reverse transcriptase (SSIII RT, Invitrogen, USA) as previously described [68]. The RT and PCR primers used in the study are presented in Table S1, "Supplementary data". PCR amplification was carried out in a total volume of $20 \mu \mathrm{l}$ using Maxima Hot Start Taq DNA polymerase (Thermo Scientific, USA), 1×PCR Buffer, $1.5 \mathrm{mM} \mathrm{MgCl}_{2}, 0.2 \mathrm{mM}$ dNTPs, $1 \times$ EvaGreen (Biotium, Hayward, USA), and 0.2 $\mathrm{mM}$ of PCR sense and antisense primers. The reaction was performed with initial preheating at $94^{\circ} \mathrm{C}$ for $4 \mathrm{~min}$ and 40 cycles of $94^{\circ} \mathrm{C}$ for $40 \mathrm{~s}, 60^{\circ} \mathrm{C}$ for $30 \mathrm{~s}, 72^{\circ} \mathrm{C}$ for $30 \mathrm{~s}$, followed by a melting point determination. The obtained PCR data were analyzed by standard Bio-Rad iQ5 v.2.0 software. For each sample, the threshold cycle $(\mathrm{Ct})$ was determined. Quantitative assessment of the level of transcripts representation and relative miRNA expression was performed by comparing the Ct values for miRNA and references U6 and Rpl30.

\subsection{Western Blot}

Cell lysates were separated in $12.5 \%$ SDS-PAGE and transferred to a PVDF membrane using a semi-dry transfer. The membranes were blocked for $18 \mathrm{~h}$ in $3 \%$ nonfat dried milk in TBST (20 mM Tris-HCl, pH 7.6, $137 \mathrm{mM} \mathrm{NaCl,} 0.1 \%$ Tween), and incubated with primary antibodies against PDCD4 (ab79405, Abcam, UK, 1:3000) and reference protein GAPDH (ab9485, Abcam, UK, 1:1000) at room temperature for $1 \mathrm{~h}$. After three washes with TBST, membranes were incubated with secondary HRP-conjugated goat anti-rabbit antibodies (ab6721, 
Abcam, UK) at room temperature for $1 \mathrm{~h}$. After three washes with TBST, proteins were detected using Chemiluminescent Reagent (ab79907, Abcam, UK).

\subsection{MTT-test and doubling time determination}

The influence of oligonucleotide 5'- $h-9 / 14$ and conjugate 5'-h-9/14 on the proliferation activity of RLS $_{40}$ cells was tested by MTT assay [69] and evaluation of the cell doubling time. After transfection with the conjugates, $\mathrm{RLS}_{40}$ cells were seeded into 96-well plates and incubated for $72 \mathrm{~h}$ under standard conditions at $37^{\circ} \mathrm{C}$ in a humidified atmosphere with $5 \% \mathrm{CO}_{2}$. MTT assay was performed as described in [70]. To evaluate the cell doubling time, at $4 \mathrm{~h}$ and $72 \mathrm{~h}$ after transfection the number of cells was counted with a cytometer. The doubling time was determined by the calculation of the number of doubling according to the equation: $\mathrm{n}=3.32 \times$ $\log (\mathrm{x} 1 / \mathrm{x} 0)$, where $\mathrm{n}$ is the number of doubling, $\mathrm{x} 0$ is the number of cells at the starting point, $\mathrm{x} 1$ is the number of cells at $72 \mathrm{~h}$ after transfection.

\subsection{Statistics}

The data obtained were statistically processed using one-way ANOVA and post-hoc Tukey test $(\mathrm{p} \leq 0.05)$. The statistics package STATISTICA version 10.0 was used for this analysis.

\section{Results}

\subsection{Design of miR-21 targeted oligonucleotides and peptide-oligonucleotide conjugates}

Among the many miRNAs already identified as regulators of neoplastic transformation and tumorigenesis, miR-21 has emerged as a key miRNA which is dysregulated and overexpressed in major types of tumour and immortalized eukaryotic cell lines. Indeed, miR-21 has been found to be implicated in almost every cancer network [71-74]. Thus miR-21 represents an attractive target for anticancer therapy, where its inhibition could greatly reduce the malignant potential of tumour cells. For this reason, we target miR-21 using POCs to perform selective silencing of this miRNA. Moreover, our target $h s a$-miR-21 of Homo sapiens (denoted from this point as miR-21) has $100 \%$ homology with the sequence of mmu-miR-21 of Mus musculus. This provides the option to carry out experiments in either human or mouse tumour models.

Taking into account that miR-21 is $22 \mathrm{nt}$ in length, the limiting factor for anti-miRNA POC design is the length of antisense oligonucleotide to form (i) a stable duplex with the target and (ii) to have potential cleavage sites in miR-21. In this respect, the design of the oligonucleotide part, to ensure selective and effective binding with the miRNA-target molecule, is an important step in creating anti-miRNA POCs. 
As a guiding component in POCs, we explored antisense oligonucleotides of different length and structure, i.e. linear antisense oligonucleotides and hairpin oligonucleotides designed on the principle of primer generation used in stem-loop PCR [67]. The hairpin oligonucleotides consist of antisense sequences ranging from 10 to 16 nucleotides; hairpins containing a fivenucleotide loop flanked by two GC pairs [75]; and an additional stem of 4 or 7 nucleotides, so that the total length of the stem was 6 or 9 bp (Fig. 1). Upon binding with miRNA, additional stabilization of the complex is achieved due to efficient stacking interactions. The complete list of oligonucleotides, used for miR-21 targeting, is given in Table 1.

The miRNA-specific conjugates were constructed based on our previous design strategies for the 'single' and 'dual' peptide-oligonucleotide conjugates [50, 51], which demonstrated efficient cleavage of the model RNA (i.e. yeast $\mathrm{tRNA}^{\text {Phe }}$ ). Such conjugates incorporated unmodified oligodeoxyribonucleotide(s) complementary to this RNA and a catalytic peptide containing [Leu-Arg] $\mathrm{n}$ building blocks, which act as a cleaving domain. Since the incorporation of an extra glycine residue in the middle of the peptide chain consistently showed the highest level of ribonuclease activity $[50,51]$, we selected the corresponding peptide -[(LeuArg $\left.)_{2} \mathrm{Gly}\right]_{2}-$ to generate these novel miRNA-specific conjugates. Based on the experimental evidence that any considerable changes in the conjugate structure (i.e. chemical modifications of the oligonucleotide part) may lead to a significant reduction of the cleavage activity [44, 76, 77], in this study we decided to preserve the 'natural' sugar-phosphate backbone of the oligonucleotide recognition moieties. Our previous studies of 'dual' conjugates [51] have illuminated an importance of the conformational flexibility on their cleavage efficiency. Therefore, in this research we incorporated a flexible aminohexyl linker between the oligonucleotide and peptide to enhance overall conformational freedom for the catalytic moiety. To achieve this, the catalytic peptide was attached via its C-terminus to the amine group of the aminohexyl linker located either at the 3'- or 5'- end of the oligonucleotide (Fig. 1). In order to avoid undesirable peptide self-conjugation and/or cyclization during the amide coupling reaction, the peptide was protected at the N-termini by an acetyl group to generate Acetyl-(LeuArg) $)_{2}-\mathrm{Gly}-(\mathrm{LeuArg})_{2}-\mathrm{Gly}-\mathrm{COOH}$ sequence. The general structure of anti-miR-21 POCs is presented in Fig. 1 showing this new type of conjugation, which has never been used before for synthesis of 'single' peptideoligonucleotide conjugates.

Two types of oligonucleotides were considered for conjugate design: (1) 3'-aminohexyl oligonucleotides, targeting the 3'-end of miR-21; these are intended to be conjugated with the peptide at the 3'-end, in order to cleave linkages at the 5' -end of miRNA; and (2) 5'-aminohexyl oligonucleotides, targeting the 5'-end of miR-21; these are intended to be conjugated with the peptide at the 5'-end, in order to perform cleavage of linkages at the 3'-end of miRNA. 


\subsection{Selection of oligonucleotides for POCs synthesis}

To find the optimal addressing component in the POC structure, screening of oligodeoxyribonucleotides was performed to evaluate the efficiency of binding to the target. The ability of the oligonucleotides to bind with $5^{\prime}-\left[{ }^{32} \mathrm{P}\right]-\mathrm{miR}-21$ (denoted after as *miR-21) was analyzed at $37^{\circ} \mathrm{C}$ by gel-retardation assay (Fig. 2). Binding efficacy of linear oligonucleotides with miR-21 at equimolar concentrations strongly depends on the length of antisense part: we observed an increase in hybridization extent from $60 \%$ for $5^{\prime}-14$ to $98 \%$ for $3^{\prime}-16$ and $5^{\prime}-16$. Hairpin oligonucleotides with the length of complementary sequence of $10-12$ nucleotides exhibit poor binding with RNA. With the increase in length of complementary sequence to 14 16 nucleotides, a significant increase in binding extent is observed, up to $97-100 \%$. We note that duplex stabilization effect of the hairpin is achieved for oligonucleotides with complementary sequence of 14 nucleotides: an increase in binding efficacy from $57 \%$ for 5'-14 to about $97 \%$ for $5 '-h-6 / 14$ and $5^{\prime}-h-9 / 14$ was observed (Fig. 2). Nevertheless, elongation of the stem from 6 to 9 bp does not lead to significant increase in binding efficacy. In the case of oligonucleotides with complementary sequence of 16 nucleotides, the duplex stabilization effect of the hairpin is not so obvious because the binding efficacy of both 5'-16 and 3'-16 reach $100 \%$ at equimolar concentration.

Based on their hybridization properties, oligonucleotides 3'-16, 3'-h-6/16, 3'- $h-9 / 16,5$ '$h-6 / 14,5$ '- $h-9 / 14,5 '-16,5$ '- $h-6 / 16$ and 5'- $h-9 / 16$ were chosen as addressing components for synthesis of POCs. Hairpin oligonucleotide 3'- $h-9 / 10$, containing a 10 -mer antisense sequence with poor binding with miR-21, was also included for synthesis and used in the study as a control. The synthesized conjugates have the same nomenclature as corresponding oligonucleotides, but shown in bold.

\subsection{POCs synthesis and characterization}

POCs, with the peptide acetyl-[(LeuArg $\left.)_{2} \mathrm{Gly}\right]_{2}$ attached to the aminohexyl linker located at either the 5'- or 3'-end of the addressing oligonucleotide via its C-terminal carboxylic group, were synthesized, purified and characterized as described in 'Materials and methods' section. The general structure of anti-miR-21 POCs and amino acid sequence of the peptide are shown in Fig. 1.

Peptide was synthesized using an Fmoc-Gly-Wang resin (C-terminal carboxylic acid) and manual solid-phase methodology utilizing the common Fmoc/tBu protocol. The detailed information on synthesis and purification protocols is given in [50].

An array of various POCs incorporating the same catalytic peptide, but different miR-21 specific oligonucleotides (see Fig. 1 and Table 1) were synthesized by activation of C-terminal 
carboxylic group of the peptide with N,N'-dicyclohexylcarbodiimide in the presence of 4dimethylaminopyridine under anhydrous conditions. The acetyl-protected $\mathrm{N}$-terminus of the peptide prevented the self-condensation of the peptide. The activated peptide was added to the DMSO-soluble cetyltrimethylammonium salt of oligonucleotide and incubated as described in 'Materials and methods' section.

Various reaction conditions (e.g. reagent excess, volume, temperature, time) were sequentially varied to find the optimum for conjugate yield, with the biggest contributory factors being minimal reaction volume and reagent excess (data not shown). Conjugates were isolated by precipitation with $4 \% \mathrm{LiClO} 4(\mathrm{w} / \mathrm{v})$ in acetone and purified by RP-HPLC. Reproducible yields between $70-90 \%$ were achieved. Identity and purity of the synthesized POCs have been confirmed by RP-HPLC, ${ }^{1}$ H-NMR and mass spectrometry (see 'Materials and methods' section and Supplementary Information).

\subsection{Hybridization properties of POCs}

The ability of conjugates to hybridize with *miR-21 was studied at $37^{\circ} \mathrm{C}$ by gelretardation assay. From the data shown in Fig. 3A, it is apparent that at 5-fold excess, all studied conjugates, except $\mathbf{3} \cdot \mathbf{h}-\mathbf{9} / \mathbf{1 0}$, bind to the target as efficiently as the corresponding oligonucleotides, demonstrating quantitative binding. Conjugates 3'-h-9/16 and 5'-h-9/16 bind to miR-21 with the formation of complexes of different stoichiometry (Fig. 3A). Detailed analysis of the concentration dependencies shows that the attachment of the peptide to an oligonucleotide decreases binding with miR-21 (Fig. 3B): at equimolar concentration, the binding efficiency of $\mathbf{5}$ '-h-9/14 is only one third of the binding efficiency of corresponding oligonucleotide, but at 5-fold excess, the binding of both oligonucleotide and conjugate reaches $100 \%$. The reduced hybridization properties of conjugates in comparison with parent oligonucleotides could be explained by (at least) two reasons. First, non-hybridized conjugates may form intermolecular complexes via self-assembly induced by electrostatic interaction between the positively charged peptide moiety of one conjugate molecule and the negatively charged oligonucleotide motif from different molecular species. This molecular assembly may decrease the effective concentration of monomeric form of conjugates in the solution, which is essential for hybridization with miRNA target. In addition, electrostatic interactions between the arginine residues of the peptide and the phosphate groups of the oligonucleotide within the same conjugate molecule may stabilise intramolecular interactions and thus induce some folded conformations, which could be detrimental for the hybridization of the conjugate with the approaching miRNA target due to an induced steric hindrance'. 


\subsection{Site-selective ribonuclease activity of POCs}

Site-selective miR-21 cleavage by POCs bearing peptide either at the 3'-end of the corresponding oligonucleotide (denoted as 3'-conjugates) or the 5'-end (denoted as 5'conjugates) was studied. This was performed at 20 - 50-fold excess of POC over RNA to ensure detection even for low cleavage extent. *miR-21 $(1 \mu \mathrm{M})$ was incubated with one of the conjugates for $0-144 \mathrm{~h}$. As a control of cleavage selectivity, conjugate 3'-h-9/10 (which was shown to be unable to form a stable duplex with miR-21) was used.

Analysis of miR-21 cleavage by 3'-conjugates shows that cleavage activity of these molecules is very low, even if a 50-fold excess of the conjugates is used. All 3'-conjugates cleave miR-21 at a single linkage $\mathrm{G}_{3} \mathrm{C}_{4}$ and cleavage efficacy does not exceed 5\% in $144 \mathrm{~h}$ (Fig. S2). In spite of the fact that we do not detect formation of stable complementary complex between miR-21 and conjugate 3'-h-9/10, this compound also cleaves miR-21 at the site $\mathrm{G}_{3} \mathrm{C}_{4}$ with similar efficacy, thus raising the question of whether the cleavage occurs within a specific POC/miR-21 complex (Fig. S2).

By contrast, 5'-conjugates exhibit high cleavage activity (Fig. 4). The cleavage extent was shown to vary from $57 \%$ to $99 \%$ at 20 -fold excess in $72 \mathrm{~h}$ (Fig. 4, Table S2).

Conjugates 5'-16, 5'-h-6/14 and 5'-h-9/14 seem to be the most efficient and were found to cleave about $65-85 \%$ of miR-21 in 24 h, whereas conjugates 5'-h-6/16 and 5'-h-9/16 cleave only $18-20 \%$ of miR-21 for the same time interval (Fig. 4C, Table S2). Kinetic curves for conjugates 5'-16, 5'-h-6/14 and 5'-h-9/14 plateau after $48 \mathrm{~h}$ at an RNA cleavage extent 93 99\%. For the same time interval, the kinetics for conjugates $\mathbf{5}$ '-h-6/16 and $\mathbf{5}$ '-h-9/16 are linear or close to linear and reach 57 and 45\%, respectively (Fig. 4C).

The half-lives calculated from the kinetics for conjugates 5'-h-9/16 and 5'-h-6/16 are 43.7 \pm 1.2 and $59.9 \pm 2.0 \mathrm{~h}$ respectively (Fig. 4D, Table S2), whereas the rates of miR-21 cleavage by conjugates 5'-16, 5'-h-6/14 and 5'-h-9/14 are significantly higher - the half-lives are $15.1 \pm 0.2,10.0 \pm 0.17$ and $17 \pm 0.4 \mathrm{~h}$, respectively (Table S2).

Figure $4 \mathrm{D}$ shows the concentration dependencies of miR-21 cleavage by POCs at time point 24 h. The most active POCs 5'-16, 5'-h-6/14 and 5'-h-9/14 exhibit similar dependencies, with a plateau reached at a POC concentration of about $10-20 \mu \mathrm{M}$. Interestingly, at this time point in concentration range $20-50 \mu \mathrm{M}$, the maximum extent of miR-21 cleavage does not exceed $60-65 \%$ (Fig. 4D). These data show that complex formation is not the rate limiting step of site-selective RNA cleavage. Significantly less active POCs display a linear concentration dependency (5'-h-9/16) or a curve which plateaus at $20 \mu \mathrm{M}$ of POC concentration (5'-h-6/16) when RNA cleavage is $20 \%$. Thus, comparison of kinetics and concentration dependencies for 
these POCs shows that the behavior of 5'-h-6/16 is similar to the most active conjugates and 5'h-9/16 exhibits a strong dependence of cleavage extent versus concentration (linear curve), while the kinetics has a tendency to plateau.

Depending on the length of antisense component of POCs, two or three cleavage sites are detected (Fig. 4A, 4B). Within the first two hours, parallel and independent cleavage of three linkages, $\mathrm{G}_{15} \mathrm{~A}_{16}, \mathrm{G}_{18} \mathrm{U}_{19}$ and $\mathrm{G}_{21} \mathrm{~A}_{22}$, for 14-mer conjugates 5'-h-6/14, 5'-h-9/14 appear; and two linkages emerge, $\mathrm{G}_{18} \mathrm{U}_{19}$ and $\mathrm{G}_{21} \mathrm{~A}_{22}$, for conjugates with a longer antisense part 5'-16, 5'-h6/16, 5'-h-9/16 (Fig. 4A, 4B, Fig. S3). Up to 72 h, the linkages located closer to the peptide are the main cleavage sites (63 - 68\% of cleavage); and as the distance from the peptide to the linkage increases, the cleavage intensity drops: for 5'-h-6/14 $G_{15} A_{16} \gg G_{18} U_{19} \gg G_{21} A_{22}$; for 5'-h-6/16 G $\mathrm{G}_{18} \mathrm{U}_{19} \gg \mathrm{G}_{21} \mathrm{~A}_{22}$ (Fig. 4A, 4B).

\subsection{Ribonuclease activity of control non-complementary POCs against miR-21}

In order to evaluate the biological activity of developed miRNases, the control conjugate 5'-luc-h-9/14 was synthesized based on the same design concept as that of the conjugate 5'-h9/14. However, the oligonucleotide part of the 5'-luc-h-9/14 control conjugate was replaced with the fragment of firefly luciferase gene, sequence of which is not found in the mammalian genome. The cleavage of miR-21 by control non-complementary conjugate $\mathbf{5}$ '-luc-h-9/14 was studied.

It was revealed that in the absence of complementary sequence within the target, the conjugate 5'-luc-h-9/14 was also able to cleave the substrate, but with much lower efficiency. The cleavage of miR-21 by this conjugate was observed at all G-X linkages along the RNA molecule with similar kinetics (Fig. 5), whereas the cleavage of miR-21 with the sequencespecific conjugate 5'-h-9/14 occurs in a different manner, with the most effective scission at G-X bonds which is closest to the peptide location. The analysis of concentration dependencies shows that the total cleavage extent of miR-21 by non-complementary conjugate $\mathbf{5}$-luc-h-9/14 is approximately 2 -fold lower than by the miR-21 specific conjugate 5'-h-9/14 (Fig. 5).

This suggests that, in the absence of complementarity, conjugate 5'-luc-h-9/14 behaves as a usual non-specific ribonuclease, which we observed in earlier works [76, 77]. This could be attributed to some type of opportunistic cleavage during transient electrostatic interactions or imperfect hydrogen bonding between the ribonuclease and RNA substrate. As soon as the complementary stretch appears within the target, this non-specific behavior is controlled, and the conjugate has no other choice than to cleave site-selectively. 


\subsection{Molecular modelling}

\section{ACCEPTED MANUSCRIPT}

In order to obtain insight into putative conjugate/miR-21 structures, a model of the 5'-h6/14 /miR-21 complex was constructed using homology and NMR structural information (see 'Materials and Methods'). A subsequent microsecond molecular dynamics simulation of the complex was performed, with the effect of aqueous solvation incorporated via generalized Born implicit water. The backbone RMSD of the complex stabilizes after $0.2 \mu \mathrm{s}$, with a minor subsequent shift at $0.65 \mu$ s (Fig. S4). The duplex and hairpin structures remain intact throughout the simulation (Fig. S5). The peptide moiety, AcO-(LeuArg) $)_{2}-\mathrm{Gly}-(\mathrm{LeuArg})_{2}-\mathrm{Gly}-\mathrm{COOH}$, forms persistent interactions with miR-21 (Fig. 6A, 6B and Fig. S5).

Specifically, the arginine residues form a network of ionic interactions with backbone phosphate groups in the 15-22 region of miR-21 (Fig. 6A, 6B). Of particular interest, the guanidino sidechains of Arg5 and Arg10 (see Fig. 1B for amino acids numbering) interact strongly with the phosphate oxygens of the $\mathrm{G}_{15} \mathrm{~A}_{16}$ site, the site which provides the major 'endpoint' cleavage product after $48 \mathrm{~h}$ of incubation. Indeed, at $1 \mu \mathrm{s}$, there $\operatorname{are} \operatorname{Arg} 10 \mathrm{H}_{\eta 1}$ and $\mathrm{H}_{\eta 2}$ distances to a $\mathrm{G}_{15} \mathrm{~A}_{16} \mathrm{P}=\mathrm{O}$ oxygen atom of 1.93 and $2.34 \AA$ respectively; for $\mathrm{Arg} 5$, these distances, to the other $\mathrm{P}=\mathrm{O}$ oxygen, are 1.68 and $2.09 \AA$ (Fig. 6A, 6B; Fig. S6). Interestingly, ancillary hydrogen bonding interactions of the $\operatorname{Arg} 10$ sidechain with the $\mathrm{N}_{7}$ and carbonyl $\mathrm{O}$ atoms of $\mathrm{G}_{15}$ are also evident from the simulation (Fig. S7). The shift in RMSD at $0.65 \mu$ s corresponds to the involvement of Arg5 in interacting with the $\mathrm{G}_{15} \mathrm{~A}_{16}$ phosphate backbone (Fig. $\mathrm{S6B}$ ) with reduced engagement of Arg8 with the base of $\mathrm{G}_{15}$ (Fig. S8).

Following Soukup and Breaker [78], it is possible to estimate a propensity for phosphodiester cleavage based on angle $\tau$, defined by the oxygen atom of the 2'-hydroxyl group, the phosphorus atom and the oxygen atom of the departing 5'-group; and on distance $d$ between the 2'-hydroxyl group and the phosphorus atom. We find here that relatively favorable values of $\tau$ and $d$ can be achieved at the $\mathrm{G}_{15} \mathrm{~A}_{16}$ site in the simulation, although not predominant (Fig. $6 \mathrm{C}$, 6D). Based on simultaneously sampled $\tau$ and $d$ values from the trajectory of $133^{\circ}$ of $3.3 \AA$ respectively, a computed in-line fitness $F$ of 0.51 is obtained using the equation of Soukup and Breaker (where a $F$ value of 1 indicates the highest possible predisposition towards cleavage, and 0 least disposed) [78]. We do note however other favorable in-line conformations are achievable at other phosphate linkages in the 15-22 region of miR-21. For example, during the MD simulation, a $(\tau, d)$ orientation of $\left(153^{\circ}, 2.9 \AA\right)$ is achieved at the $\mathrm{G}_{18} \mathrm{U}_{19}$ site, the second preferred site of cleavage found experimentally (Fig. 4 and S9), yielding an in-line fitness $F$ of 0.86. Indeed, complete sampling of the complex network(s) of ionic contacts may be to some extent limited here by the use of an implicit solvent model, which could overestimate the 
stability of these interactions [79]. While future work could consider more computationally demanding explicit solvent calculations, this molecular dynamics simulation nevertheless is indicative of potentially reactive conformations of the conjugate in its hybrid with miR-21.

\subsection{Effect of conjugate 5'-h-9/14 on the level of miR-21 in lymphosarcoma cells RLS 40}

From the point of view of therapeutic importance, the principal question is to ascertain whether the developed miRNases are able to inactivate miR-21 in the biological system.

The intracellular accumulation of therapeutic compounds is a very important point. For this reason prior to cellular experiments the accumulation of FITC-labeled peptideoligonucleotide conjugate 5'-h-9/14 (FITC-5'-h-9/14) in murine lymphosarcoma cells RLS 40 and human cervical cancer cells KB-8-5 mediated by Lipofectamine 2000 was studied using flow cytometry and confocal microscopy. Recently, we have shown that the treatment of murine lymphosarcoma cells with Lipofectamine decreased their proliferation rate by no more than $10 \%$, which was within the experimental error of MTT assay [70]. We found that $4 \mathrm{~h}$ after transfection of cells with $1 \mu \mathrm{M}$ FITC-5'-h-9/14/Lipofectamine lipoplexes, 87\% of RLS R $_{40}$ cells and 86\% of KB-8-5 cells became FITC-positive with the average cell fluorescence of 12.6 and 40 RFU for $\mathrm{RLS}_{40}$ and KB-8-5 cells, respectively (Fig. S10). The difference in RFU values between the studied cells can be attributed to the dissimilarity in the cell size. Indeed, human KB-8-5 cells are considerably larger then RLS $_{40}$ cells, and thus accumulate greater amount of FITC-POC leading to a stronger fluorescence signal in comparison with murine cells. It was also shown in these experiments that in the absence of the transfection agent FITC-5'-h-9/14 was able to penetrate aprox. $2 \%$ of cells only.

Confocal microscopy showed that FITC-5'-h-9/14-POC/Lipofectamine lipoplexes are effectively accumulated in the cytoplasm of KB-8-5 cells $4 \mathrm{~h}$ after transfection, but did not enter the nucleus (Fig. S11). Thus, both flow cytometry and confocal microscopy showed that the conjugation of oligonucleotides with short peptides neither noticeably affect the lipoplexes formation nor alter their cellular localization.

The ability of the conjugates to affect miR-21 level in tumour cells was tested using conjugates 5'-h-6/14 and 5'-h-9/14 and mouse lymphosarcoma cells RLS $_{40}$ [80], which are characterized by elevated levels of miR-21. The concentration dependence of miR-21 suppression in tumor cells by the conjugate 5'-h-6/14 $(0.1-5 \mu \mathrm{M}) 24 \mathrm{~h}$ after transfection of cells with the conjugate/Lipofectamine complexes measured by stem-loop qPCR is shown in Fig. S12. It can be seen that control conjugate 5'-luc-h-9/14 did not decrease miR-21 level, whereas even a $0.5 \mu \mathrm{M}$ concentration of $\mathbf{5}$ - $\mathbf{- h}-\mathbf{6} / \mathbf{1 4}$ resulted in a noticeable decrease in miR-21. The most effective dose was found to be $1 \mu \mathrm{M}$, and any further increase in $\mathbf{5}$ '-h-6/14 concentration from 1 
to $5 \mu \mathrm{M}$ did not affect the efficiency of miR-21 silencing. Based on this data, $1 \mu \mathrm{M}$ concentration of the conjugate was chosen for testing its biological activity in the following experiments.

In experiments on the kinetics of miR-21 suppression RLS $_{40}$ cells were transfected with 1 $\mu \mathrm{M}$ oligonucleotide 5'-h-9/14, control conjugate 5'-luc-h-9/14 or anti-miR-21 conjugate 5'-h9/14 precomplexed with Lipofectamine 2000 and the level of miR-21 was evaluated at 24, 48 and $72 \mathrm{~h}$ after transfection using stem-loop qPCR. Analysis of qPCR data (Fig. 7A) shows that $24 \mathrm{~h}$ post transfection, conjugate $\mathbf{5}$-h-⿳⺈/14 provides more than a two-fold reduction in miR-21 level in tumour cells; this is statistically significant in comparison with all groups $(p=0.0002$ for 5'-h-9/14 $v s$ control, LF and 5'-h-9/14 asON; $p=0.0003$ for 5'-h-9/14 vs 5'-luc-h-9/14) and to the time point $72 \mathrm{~h}$ the level of miRNA is restored to $80 \%$ from the initial level (Fig. 7A). Conjugate 5'-luc-h-9/14 causes only a slight reduction in the level of miR-21 seen at $24 \mathrm{~h}$ after transfection, and this difference is statistically insignificant (Fig. 7A). The asON 5 ' $h-9 / 14$ does not decrease miR-21 levels or it cannot be detected by qPCR analysis (Fig. 7A).

To confirm the specificity of miR-21 silencing by the conjugate, the level of the other miRNAs, let7-g, miR-17 and miR-18a was also monitored. The study of expression of let7-g, miR-17 and miR-18a in RLS $_{40}$ cells shows that there is no statistically significant decrease in the level of miRNAs after transfection, confirming the selectivity of miR-21 silencing with the conjugate 5'-h-9/14 (Fig. 7B, Fig. S13).

\subsection{Effect of conjugate 5 '-h-9/14 on the level of miR-21 protein target PDCD4 in RLS $_{40}$ lymphosarcoma cells}

The decrease in the level of oncogenic miR-21 in tumour cells under the effect of the conjugate should promote the restoration of normal activity of tumour-suppressive target genes of miR-21 and as a consequence their protein products. Due to the decline in miRNA concentration in the cells, changes in the level of target proteins are usually observed in approximately $48-72 \mathrm{~h}$. In order to determine if there was any alteration in the level of protein PDCD4, the direct target of miR-21, Western blot analysis was performed $48 \mathrm{~h}$ after transfection of $\mathrm{RLS}_{40}$ cells with $1 \mu \mathrm{M}$ oligonucleotide 5'-h-9/14, control conjugate 5'-luc-h-9/14 or antimiR-21 conjugate 5'-h-9/14 (Fig. 7C, 7D). The data obtained show that there is no statistically significant change in the level of PDCD4 in tumour cells incubated with control conjugate 5'luc-h-9/14 or antisense oligonucleotide $5 '-h-9 / 14$. By contrast, in the cells incubated with antimiR-21 conjugate 5'-h-9/14 (when the reduction in miR-21 level is observed), the level of PDCD4 increases 1.9-fold in comparison with control (Fig. 7C, 7D).

\subsection{Effect of conjugate 5 '-h-9/14 on proliferative potential of $\operatorname{RLS}_{40}$ lymphosarcoma cells}


The decrease in the level of oncogenic miR-21 and reactivation of its target proteins in tumour cells under the effect of the conjugate should reverse the malignant behavior of tumour cells, in particular inhibiting cell growth, inducing apoptosis and reducing the invasive and migratory properties of the cells. To assess the presence of conjugate-mediated effects on the behavior of tumour cells, we examined the ability of tumour cells to proliferate after exposure to anti-miR-21 conjugate. For this purpose RLS $_{40}$ cells were transfected with $1 \mu \mathrm{M}$ oligonucleotide 5'-h-9/14, control conjugate $\mathbf{5}$ '-luc-h-9/14 or anti-miR-21 conjugate $\mathbf{5}$ '-h-9/14 using Lipofectamine 2000. To determine the growth rate of lymphosarcoma cells, the doubling time of cell populations was calculated by counting the number of cells $72 \mathrm{~h}$ after transfection. Data analysis shows that cell doubling time for intact $\mathrm{RLS}_{40}$ cells is $22.3 \pm 0.7 \mathrm{~h}$. For cells treated with Lipofectamine 2000 or control conjugate 5'-luc-h-9/14, this parameter is $22.7 \pm 0.9$ and $22.9 \pm 1.0$ $h$, respectively. Transfection of $\mathrm{RLS}_{40}$ cells with anti-miR-21 antisense oligonucleotide 5'- $h-9 / 14$ results in an increase in the cell doubling time to $25.7 \pm 1.0 \mathrm{~h}$. The most noticeable decrease in cell growth rate is observed for cells treated with anti-miR-21 conjugate 5'-h-9/14, where the cell doubling time increases to 1.4 -fold and is $33.3 \pm 2.2 \mathrm{~h}$. The data obtained are supported by an analysis of the proliferative properties of lymphosarcoma cells by MTT assay (Fig. 7E). Data analysis reveals that transfection of cells with Lipofectamine 2000 or control conjugate 5'-luc-h9/14 causes to no statistically significant change in their proliferative properties. Antisense oligonucleotide exerts a 30\% suppression of proliferation of lymphosarcoma cells $(p=0.00012$ for 5'-h-9/14 asON vs control, Fig. 7E). In the case of conjugate 5'-h-9/14, the viability of tumour cells falls to $50 \%$ as compared to control conjugate ( $p=0.0003$ for $\mathbf{5}$-h- $\mathbf{h} / \mathbf{1 4}$ vs control, Fig. 7E) and the effect is 1.4-fold stronger as compared with antisense oligonucleotide ( $p=0.05$ for 5'-h-9/14 vs 5'-h-9/14 as ON, Fig. 7E).

\section{Discussion}

The present investigation is focused on the development of metal-free miRNA-specific peptide-oligonucleotide conjugates, intended for miRNA degradation and silencing in tumour cells without the need for exogenous species (e.g., metal ions). To date, the main method for miRNA inhibition is antisense technology that uses oligonucleotides complementary to miRNA for performing either RNA degradation by endogenous RNase $\mathrm{H}$ or steric blockage. The latter mechanism of action is more prevalent because chemical modifications required for improvement of nuclease stability and affinity of oligonucleotides to the target molecule lead to a loss of the ability to recruit endogenous RNase $\mathrm{H}$, but provide steric blockage of target 
miRNA. Nevertheless the approaches aimed at destruction of miRNAs seem to be preferable due to irreversibility and therefore higher efficiency.

MiRNA-specific POCs, termed 'miRNases', represent a hybrid technology that combines (i) specific recognition and binding with target miRNA via antisense oligonucleotide and (ii) cleavage by the conjugated artificial ribonuclease. Preceding investigations of sequence-specific artificial ribonucleases have been largely limited to the use of model RNA targets (tRNAs, synthetic RNA-substrates, etc.) [42-51, see reviews 53, 54] with limited attempts to apply these promising strategy to biologically or clinically relevant systems. Only a few examples of application of metallo-dependent sequence-specific artificial nucleases for degrading of biologically significant RNA molecules have been described [81, 82]. It has been reported that in vitro transcripts of 571- and 2977-nucleotide long human c-raf-1 RNA were efficiently cleaved by 2'-methoxyethoxy-modified oligonucleotides bearing a europium complex in a sequence specific manner [81]. The scission technique based on acridine-modified DNA and lanthanide(III) ion as a catalyst was shown to promote sequence-specific cleavage of a 40-mer fragment of human apolipoprotein E gene; this allowed identification of a single nucleotide polymorphism at the site of interest [82]. Application of sequence-specific conjugates in cell culture has been explored only in a few studies, demonstrating the advantage of applying of conjugates against corresponding antisense oligonucleotides in modulating RNA [83, 84]. The lanthanide macrocycle complex, Eu(THED) ${ }^{3+}$, attached to antisense oligonucleotide potentiated the inhibition of ICAM-1 protein expression in endothelial cells more efficiently than unconjugated oligonucleotide [83]. Antisense phosphorothioate oligonucleotide bearing the 5'imidazole group provided sequence-specific cleavage of a complementary target sequence in the gag mRNA from HIV-1 and inhibited the replication of HIV-1 in MT-4 cells more effectively than the parent antisense oligonucleotide [84].

Since miRNA molecules are short, the design of site-selective chemical nucleases for miRNA targeting represents a challenging task: an appropriate balance needs to be achieved between the length of the miRNA-binding component, sufficient for efficient complex formation, and a fragment of RNA accessible for cleavage by the conjugate.

To date, there is only one published work describing a miRNA-targeted metallodependent ribonuclease [85]. Conjugates of peptide nucleic acid (PNA) - PEG-PNA-PEG with HGG. $\mathrm{Cu}$ or DETA as cleaving domains, targeted to the hsa-miR-1323, demonstrated effective cleavage of RNA [85]. These conjugates engaged with the miRNA molecule and performed cleavage, with the release of one or two nucleotides from the 3'-end of the miRNAtarget (elongated by 5 nucleotides). In spite of clear success demonstrated by these metaldependent artificial ribonucleases, they may potentially suffer from the risk of metal-loss from 
the coordinating ligand and uncontrolled diffusion of metal ions, which may lead to degradation of non-target biopolymers and cause undesirable toxicity.

Here, for the first time we apply a metallo-independent peptide-oligonucleotide chemical ribonuclease towards a clinically relevant biological target - miRNA-21. The oligonucleotides of two different structures were used for the design of the addressing domain of miRNA-targeting POCs - linear and hairpin oligonucleotides with the length of complementary part ranging from 10 to 16 nucleotides. The analysis of hybridization properties of oligonucleotides has shown that oligonucleotides with a length less than 14 nucleotides are not suitable for conjugate engineering due to very weak binding affinity for the target miR-21. We demonstrated that hairpin oligonucleotides with a 14-mer complementary part exhibit significantly enhanced hybridization properties in comparison with linear ones; however, elongation of the stem in the hairpin oligonucleotide from 6 to 9 nucleotides does not provide any advantage for binding. The addition of the hairpin to the 16-mer oligonucleotides $5^{\prime}-h-6 / 16$ and 5 '- $h-9 / 16$ does not increase its binding affinity as the binding efficiency of linear 16-mer oligonucleotide is almost $100 \%$. Therefore, linear and hairpin oligonucleotides with the length of the complementary part of 14 and 16 nucleotides were selected for POC synthesis.

Screening of the miR-21 cleaving activity of all designed 3'- and 5'-POCs was performed under large excess of POCs over the target to ensure that even faint cleavage would not be missed. Analysis of ribonuclease activity of 3'-POCs shows that this type of conjugate is not able to perform effective miR-21 cleavage. We can assume that the conjugate, which is obtained through attachment of the peptide at the 3'-end of oligonucleotide, does not form the effective intramolecular contacts between the oligonucleotide and peptide required for generation of a catalytically active conformation. Analysis of ribonuclease activity of 5'-POCs shows that this type of conjugate provides effective miR-21 cleavage at G-X bonds exceptionally and that the main cleavage sites are located near the point of peptide attachment. POCs 5'-16, 5'-h-6/14 and 5'-h-9/14 are the most effective and the total cleavage extent of miR-21 by these POCs reaches 100\% (Fig. 4, Table S2). Interestingly, POCs 5'-h-6/16 and 5'-h-9/16, which bear the elongated 2 nucleotides RNA-binding part, cleave miR-21 less efficiently: cleavage reached only 57-83\% (Fig. 4, Table S2). Several factors may be responsible. RNA cleavage by the peptideoligonucleotide conjugate is a complex, multi-step process that involves (i) the hybridization via Watson-Crick hydrogen bonding and (ii) the formation of the catalytically-active conformation followed by (iii) the catalytic act itself. Our recent data $[50,51,76,77]$ clearly demonstrate that even slight structural modifications of conjugates (i.e. variations in oligonucleotide length and composition as well as change of accessibility and base composition of the RNA cleavage sites) may dramatically affect the catalytic efficiency of the such molecules. In the case of 5'-h-6/16 
and 5'-h-9/16 POCs, the antisense part of the conjugate was elongated from 14 to 16 nucleotide residues thus leading to shortening of the target single-stranded region of miR-21 within the hybridized complex. It was shown earlier [51] that narrowing of the RNA single-stranded target region upon binding with the conjugate may result in substantial decrease or even complete loss of catalytic activity, presumably due to reduced conformational freedom for the catalytic peptide. Additionally, the most accessible bond to the cleavage by POCs 5'-h-6/14 and 5'-h-9/14 seems to be G-A, whereas POCs 5'-h-6/16 and 5'-h-9/16 tend to attack G-U bond due to elongation of the oligonucleotide part, which is known to be less sensitive to the cleavage by nucleases. Finally, due to reduced conformational flexibility, the elongated duplexes miR-21/5'-h-9/16 and miR-21/5'-h-6/16 may obstruct the formation of the in-line conformation that is essential for cleavage to occur [50, 51]. Although the ribonuclease activity seen for 5'-16, 5'-h-6/14 and 5'-h9/14 conjugates is very similar, hairpin conjugates seem to be more advantageous for application in cells. First, the only target of hairpin conjugates is the mature miRNA molecule. Also, whereas conjugate 5'-16 provides cleavage of the tail region of miRNA, conjugates 5'-h-6/14 and 5'-h-9/14, possessing about the same efficiency of binding to the miRNA-target, catalyze the cleavage close to the middle part of the miRNA molecule, which can result in the loss of miRNA function with higher probability and reliability.

The specificity of conjugates deserves special attention. The developed nucleases mimic T1 RNase specificity and perform cleavage exclusively at G-X linkages within the RNA target. Previously we have shown that when the peptide $\left[(\operatorname{LeuArg})_{2} \mathrm{Gly}\right]_{2}$ was attached to an oligonucleotide through N-terminus with a linker of zero length, the conjugates demonstrated Pyr-A specificity [50]. However, as soon as the type of conjugation is changed by introducing a new attachment point (i.e. via peptide $\mathrm{C}$-terminus) by incorporation of the flexible linker into the conjugate structure, the specificity of chemical nucleases is switched to G-X. Previously, G-X specificity of RNA cleavage was observed for specially designed non-site selective artificial ribonuclease pep-9 $[76,77]$ and 'dual' conjugates targeted to tRNA, both contained long flexible linkers, and the attachment via $\mathrm{C}$ - and $\mathrm{N}$-terminus of the peptide was used [51].

It is worth considering in more detail the precise site-selectivity of the developed conjugates: the most efficient cleavage is accomplished at the phosphodiester bonds adjacent to the peptide attachment point and cleavage efficiency decreases with the remoteness from the reactive group. Nevertheless, we cannot rule out completely the possibility of formation of imperfect complexes of conjugates with RNA molecules: it was revealed that noncomplementary conjugate $\mathbf{5}$-luc-h-9/14 performs non-site-selective cleavage of miR-21 however with much reduced efficiency (Fig. 5). 
The preferential specificity of RNA cleavage by POCs at phosphodiester bonds after guanine residues can be explained by the high affinity of arginine to guanine. Arginine can form hydrogen bonds with acceptor groups in the RNA molecule such as phosphate oxygens, the 2'$\mathrm{OH}$ oxygen of ribose, and acceptor groups in nucleobases $\left(\mathrm{Gua} \mathrm{O}_{6}\right.$ and $\mathrm{N}_{7}$, Ura $\mathrm{O}_{4}$ in the major groove, Gua $\mathrm{N}_{3}$ and $\mathrm{Ura}_{2}$ in the minor groove). Specific Arg-Gua recognition was widely shown. With the example of onconase, it was shown that replacement of Glu91 by an arginine residue in an onconase binding centre that specifically binds with guanine nucleobase in d(AUGA) increased the guanine preference and afforded an onconase variant with the highest known $\mathrm{k}_{\text {cat }} / \mathrm{K}_{\mathrm{M}}$ value [86]. A direct interaction between an arginine residue Arg144 in the active site of $E$. coli prolyl-tRNA synthetase and the $\mathrm{G} 72$ residue in the acceptor stem of tRNA ${ }^{\text {Pro }}$ was found to be a key contact providing the allosteric interaction between the anticodon domain and the aminoacylation active site [87]. It was shown that the structural basis for RNA recognition by ZRANB2 protein was the formation of a special network of hydrogen bonds between the GGUcontaining ssRNA-motif and Arg81 and Arg82 of ZRANB2 via bidentate interactions of both Gua with side chains of arginines [88].

Indeed, here from $1 \mu$ s molecular dynamics simulations of the hybridized complex between 5'-h-6/14 and miR-21, we found that strong interactions are formed between the Arg5 and Arg10 sidechains of the peptide with the phosphate oxygens of the main cleavage site on miR-21, $\mathrm{G}_{15}-\mathrm{A}_{16}$. Additional hydrogen bonding by Arg10 with the $\mathrm{N}_{7}$ and $\mathrm{O}_{6}$ atoms of $\mathrm{G}_{15}$ is also observed over the course of the simulation (Fig. 6A, 6B). The overall conformation of the complex from the microsecond trajectory displays tight binding of the oligonucleotide part of the POC with the target RNA, forming a network of ionic and hydrogen bonding contacts between the peptide and nucleotide residues (Fig. 6A, 6B). A similar pattern of interactions was observed for $\mathrm{G}_{18}-\mathrm{U}_{19}$ (Fig. S9).

Experimental data showed that it is formation of the complex that leads to effective siteselective cleavage, rather than cleavage from solution (Fig. 5). Non-selective cleavage could take place due to the binding of the arginine residues of the peptide with so-called arginine binding sites, known to be GX or GGX motifs, especially GGU. Conformational stress of miRNA in the sites of these non-sequence-selective POCs binding lead to proximity of the 2'-OH and phosphate groups, with formation of an "in-line"-like conformation that facilitates internal transesterification. This process is not effective, since only faint cleavage is observed at $\mathrm{G}_{3} \mathrm{C}_{4}$ and $\mathrm{G}_{21} \mathrm{~A}_{22}$ sites.

The most significant result of this study lies in the fact that the developed conjugates are able to reduce the level of miR-21 in tumour cells. This results in reactivation of target protein PDCD4 and inhibition of cell proliferation (Fig. 7). At the same time, we do not observe a 
decrease in the levels of ACCEPTED MANUSCRIPT

decrease in the levels of miR-21 after tumor cell exposure to asON $5^{\prime}-h-9 / 14$. The study of stability of asON and corresponding conjugate in 10\% serum shows that during the first $4 \mathrm{~h}$ conjugate is approximately 2 -fold more stable than asON, and after this time both asON and conjugate are completely degraded (Fig. S14). This increase in the serum stability of the conjugate is not a reason to believe that the effect of the conjugate is based on the protective effect of the peptide.

As a recognition domain in the structure of conjugates, we used non-modified DNA oligonucleotide, and the degradation of miRNA in the cell can occur as a result of engaging of intracellular RNase H. Our findings show that the level of specific downregulation of miR-21 by the action of the conjugate is higher than the effect of antisense oligonucleotide. In this regard, one question is whether the decrease in miR-21 level is realized either (i) at the expense of the conjugate's ability to function or (ii) we observe an additive effect, composed of nuclease activity of the conjugate and RNase H-mediated cleavage of miRNA in heteroduplex. Experiments on the cleavage of duplex miR-21/5'-h-9/16 by RNase $\mathrm{H}$ show that the presence of peptide in the miRNase scaffold affects RNase H-activity and causes 2-fold decrease in miR-21 cleavage by RNase $\mathrm{H}$ within this complex. Nevertheless the total cleavage of miR-21 by RNase $\mathrm{H}$ in complex miR-21/5'-h-9/16 is rather notable: $43 \%$ vs $97 \%$ in complex miR-21/5' $-h-9 / 16$ (Fig. S15). The contribution of RNase $\mathrm{H}$ into the degradation of miRNA in tumour cells can be considered as a positive event, as we may assume that it can facilitate dissociation of miR-21 fragments from the complex with the conjugate and promote the catalytic mode of action, thereby enhancing the inhibitory effect of the conjugate. Regardless of the possible RNase $\mathrm{H}$ contribution to the intracellular activity of conjugate, the obtained effect is comparable with the effect of anti-miRNA antisense oligonucleotides widely studied in recent years. It has been shown that chemically modified phosphorothioate and 2'-O-methyl oligonucleotides promote 2fold decrease in miR-21 levels in various cell lines that leads to an increased expression of miR21 protein targets such as PDCD4, PTEN and TPM1, up to 2-3-fold [89, 90], 2.2-fold [91] and 1.4-fold [92], respectively. Comparing the results obtained earlier with the data obtained in this work, it can be stated that the efficiency of engineered miRNases is not inferior to the activity of the oligonucleotides previously proposed.

Due to the fact that we observed some cleavage of miR-21 by non-complementary (control) POC 5'-luc-9/14 in vitro, it raises the question of off-target effects of the developed miRNAses in cells. It is worth mentioning that cleavage of miR-21 by non-complementary (control) POC was detected at relatively high concentration of the control conjugate (i.e. at 20-30 $\mu \mathrm{M})$, which corresponded to 20-30 molar excess of the conjugate over miR-21 substrate $(1 \mu \mathrm{M})$. In the in vitro and ex vivo experiments, the concentration of the conjugates was reduced to $1 \mu \mathrm{M}$. 
At this concentration, the level of non-specific cleavage of miR-21 with 5'-luc-9/14 did not exceed $1-2 \%$, which was comparable with the spontaneous RNA cleavage during the incubation. Taking into account a very strong hybridization affinity of the anti-miR-21 conjugates towards the miR-21 driven by the fully complementary oligonucleotide recognition motif incorporated in their structure, we expect this non-specific cleavage to be minimized or completely avoided in vivo, so that the targeted cleavage of miR-21 will dominate catalysis.

In order to further confirm the absence of noticeable off-target effect for the developed POCs, we examined the expression levels of several other miRNAs let7-g, miR-17 and miR-18a, which do not contain sequences complementary to those of the designed conjugates. From the presented data (Fig. 7B and Fig. S13) it is seen that there is no statistically significant difference between the test samples and the controls. Moreover we compared the expression profile of several housekeeping genes, such as Gapdh, Ubc, Rpl30, Hprt1, Ywhaz and U6 in RLS 40 cells after the treatment with POCs. To confirm the stability of the selected reference genes for all studied samples (LF, luc-h-9/14, 5'-h-9/14 asON and 5'-h-9/14 POC) the M-values were calculated (primary data not shown). We found that the differences between the genes were not more than 10-15\%, confirming the absence of non-specific effect of POC on gene expression.

Thus, designed miRNases performed in vitro cleavage of non-complementary RNAsubstrates exhibited no off-target effects when transfected into the cells: we show that 5'-h-9/16 has no effect on the levels of several miRNAs as well as house-keeping genes while downregulating target miR-21 (Fig. 7). This selectivity is provided by high affinity of the specifically designed oligonucleotides of the miRNase to the target RNA.

\section{Conclusion}

In this study, we design novel metallo-independent miRNA-specific artificial ribonucleases ('miRNases'), incorporating oligonucleotide recognition motifs and catalytic peptide. These miRNases were demonstrated to cleave site-selectively their complementary miRNA-target with high efficiency leading to a detectable, statistically significant reduction of miRNA level in tumour cells. This seems to trigger a subsequent restoration of the expression of miR-targeted proteins and negatively affect tumour cell proliferation. We also provided here a structural insight into the interactions between miRNases and miR-21 using molecular modelling simulations to offer a design platform for future development of novel, more efficient structural variants. Among the currently developed strategies oriented to suppress miRNA functioning, miRNases may take its well-deserved place in the field of development of anti-miRNA agents as an independent approach. Regarding future potential, miRNases may be a prospective candidate 
for drug development in cases where overexpression of particular miRNAs is associated with a disease state.

\section{Author contributions}

O.A.P. conducted the cleavage assays, performed the experiments with tumour cells and drafted the manuscript. E.V.B. conducted the synthesis, purification and full characterization of the peptide and conjugate samples. S.K.M. carried out the RNA labeling, conducted gel-shift and cleavage assays and analysed obtained data. N.L.M performed statistical analysis of data, coordinated the study and participated in the manuscript preparation. L.T.T. and K.K.B. carried out MD simulations and analysed the data. R.A.B. supervised L.T.T. and K.K.B. and provided guidance in molecular simulations and data interpretation. E.V.B., M.A.Z. and V.V.V. conceived the project, developed the experimental concept, design and supervised the study, data interpretation, and manuscript preparation.

All authors contributed to writing the specific parts of the paper and approved the final version of the manuscript.

\section{Acknowledgements}

This research has been supported by the Russian Science Foundation (Grant No. 14-44-00068), BBCRC (Grant No. BB/K012622/1) and EPSRC (Grant No. EP/E003400/1). The authors would like to thank Dr. Aled Williams for synthesis of 3'-conjugates, and Dr. Maria I. Meschaninova for synthesis of miR-21. The authors would like to thank Prof. David J. Clarke for fruitful discussions and manuscript editing. The authors are grateful to the EPSRC National Mass Spectrometry Centre in Swansea for MS analysis of the peptide and peptide-oligonucleotide conjugate samples.

\section{Disclosure of potential conflicts of interest}

The authors declare no conflict of interest. 


\section{REFERENCES}

[1] E.L. Vegter, P. van der Meer, L.J. de Windt, Y.M. Pinto, A.A. Voors, MicroRNAs in heart failure: from biomarker to target for therapy, Eur J Heart Fail. 18 (2016) 457-468.

[2] L.P. Garo, G. Murugaiyan, Contribution of MicroRNAs to autoimmune diseases, Cell Mol Life Sci. 73 (2016) 2041-2051.

[3] L.M. Bekris, J.B. Leverenz, The biomarker and therapeutic potential of miRNA in Alzheimer's disease, Neurodegener Dis Manag. 5 (2015) 61-74.

[4] G. Hutvanger, P.D. Zamore, A microRNA in a multiple-turnover RNAi enxyme complex, Science. 297 (2002) 2056-2060.

[5] D.P. Bartel, MicroRNAs: target recognition and regulatory functions, Cell. 136 (2009) 215233.

[6] R. Garzon, G. Marcucci, C.M. Croce, Targeting microRNAs in cancer: rationale, strategies and challenges, Nat Rev Drug Discov. 9 (2010) 775-789.

[7] V. Ambros, The functions of animal microRNAs, Nature. 431 (2004) 350-355.

[8] M. Boehm, F.J. Slack, MicroRNA control of lifespan and metabolism, Cell Cycle. 5 (2005) 837-840.

[9] J. Lu, G. Getz, E.A. Miska, E. Alvarez-Saavedra, J. Lamb, D. Peck et al, MicroRNA expression profiles classify human cancers, Nature. 435 (2005) 834-838.

[10] S. Volinia, G.A. Calin, C.G. Liu, S. Ambs, A. Cimmino, F. Petrocca et al, A microRNA expression signature of human solid tumors defines cancer gene targets, Proc Natl Acad Sci U S A. 103 (2006) 2257-2261.

[11] R. Kumarswamy, I. Volkmann, T. Thum, Regulation and function of miRNA-21 in health and disease, RNA Biol. 8 (2011) 706-713.

[12] S.L. Romero-Cordoba, I. Salido-Guadarrama, M. Rodriguez-Dorantes, A. Hidalgo-Miranda, miRNA biogenesis: biological impact in the development of cancer, Cancer Biol Ther. 15 (2014) $1444-1455$.

[13] P.P. Medina, F.J. Slack, MicroRNAs and cancer: an overview, Cell Cycle. 7 (2008) 24852492.

[14] A. Lujambio, S.W. Lowe, The microcosmos of cancer, Nature. 482 (2012) 347-355.

[15] B.D. Adams, A.L. Kasinski, F.J. Slack, Aberrant regulation and function of microRNAs in cancer, Curr Biol. 24 (2014) 762-776.

[16] D. Bonci, V. Coppola, M. Musumeci, A. Addario, R. Giuffrida, L. Memeo et al, The miR15a-miR-16-1 cluster controls prostate cancer by targeting multiple oncogenic activities, Nat Med. 14 (2008) 1271-1277. 
[17] Y. Akao, Y. Nakagawa, T. Naoe, Let-7 microRNA functions as a potential growth suppressor in human colon cancer cells, Biol. Pharm. Bull. 29 (2006) 903-906.

[18] S. Michelfelder, M. Trepel, Adeno-associated viral vectors and their redirection to cell-type specific receptors, Adv. Genet. 67 (2009) 29-60.

[19] J. Kota, R.R. Chivukula, K.A. O'Donnell, E.A. Wentzel, C.L. Montgomery, H.W. Hwang et al, Therapeutic microRNA delivery suppresses tumorigenesis in a murine liver cancer model, Cell. 137 (2009) 1005-1017.

[20] K. Gumireddy, D.D. Young, X. Xiong, J.B. Hogenesch, Q. Huang, A. Deiters, Smallmolecule inhibitors of microrna miR-21 function, Angew Chem. Int. Ed Engl. 47 (2008) 74827484.

[21] M.S. Ebert, J.R. Neilson, P.A. Sharp, MicroRNA sponges: competitive inhibitors of small RNAs in mammalian cells, Nat. Methods. 4 (2007)721-726.

[22] M.S. Ebert, P.A. Sharp, MicroRNA sponges: progress and possibilities, RNA. 16 (2010) 2043-2050.

[23] W.Y. Choi, A.J. Giraldez, A.F. Schier, Target protectors reveal dampening and balancing of Nodal agonist and antagonist by miR-430, Science. 318 (2007) 271-274.

[24] J. Xiao, B. Yang, H. Lin, Y. Lu, X. Luo, Z. Wang, Novel approaches for gene-specific interference via manipulating actions of microRNAs: examination on the pacemaker channel genes HCN2 and HCN4, J Cell Physiol. 212 (2007) 285-292.

[25] Z. Wang, The principles of MiRNA-masking antisense oligonucleotides technology, Methods Mol Biol. 676 (2011) 43-49.

[26] A. Boutla, C. Delidakis, M. Tabler, Developmental defects by antisense-mediated inactivation of micro- RNAs 2 and 13 in Drosophila and the identification of putative targets, Nucleic Acids Res. 31 (2003) 4973-4980.

[27] K.A. Lennox, M.A. Behlke, Chemical modification and design of anti-miRNA oligonucleotides, Gene Ther. 18 (2011) 1111-1120.

[28] A.L. Liang, T.T. Zhang, N. Zhou, C.Y. Wu, M.H. Lin, Y.J. Liu, miRNA-10b sponge: An anti-breast cancer study in vitro, Oncol Rep. 35 (2016) 1950-1958.

[29] S. Gao, H. Tian, Y. Guo, Y. Li, Z. Guo, X. Zhu et al, miRNA oligonucleotide and sponge for miRNA-21 inhibition mediated by PEI-PLL in breast cancer therapy, Acta Biomater. 25 (2015) 184-193.

[30] J. Jung, C. Yeom, Y.S. Choi, S. Kim, E. Lee, M.J. Park et al, Simultaneous inhibition of multiple oncogenic miRNAs by a multi-potent microRNA sponge, Oncotarget. (2015) 620370 20387. 
[31] T. Zhang, Y. Hu, J. Ju, L. Hou, Z. Li, D. Xiao et al, Downregulation of miR-522 suppresses proliferation and metastasis of non-small cell lung cancer cells by directly targeting DENN/MADD domain containing 2D, Sci Rep. 6 (2016) 19346.

[32] K.A. O'Donnell, E.A. Wentzel, K.I. Zeller, C.V. Dang, J.T. Mendell, C-Myc-regulated microRNAs modulate E2F1 expression, Nature. 435 (2005) 839-843.

[33] I.A. Asangani, S.A. Rasheed, D.A. Nikolova, J.H. Leupold, N.H. Colburn, S. Post et al, MicroRNA-21 (miR-21) post-transcriptionally downregulates tumor suppressor Pdcd4 and stimulates invasion, intravasation and metastasis in colorectal cancer, Oncogene. 27 (2008) 2128-2136.

[34] T. Li, D. Li, J. Sha, P. Sun, Y. Huang, MicroRNA-21 directly targets MARCKS and promotes apoptosis resistance and invasion in prostate cancer cells, Biochem Biophys Res Commun. 383 (2009) 280-285.

[35] M.M. Fabani, C. Abreu-Goodger, D. Williams, P.A. Lyons, A.G. Torres, K.G. Smith et al, Efficient inhibition of miR-155 function in vivo by peptide nucleic acids, Nucleic Acids Res. 38 (2010) 4466-4475.

[36] W. Kong, L. He, M. Coppola, J. Guo, N.N. Esposito, D. Coppola et al, MicroRNA-155 regulates cell survival, growth, and chemosensitivity by targeting FOXO3a in breast cancer, $\mathbf{J}$ Biol Chem. 285 (2010) 17869-17879.

[37] X.D. Zhao, W. Zhang, H.J. Liang, W.Y. Ji, Overexpression of miR -155 promotes proliferation and invasion of human laryngeal squamous cell carcinoma via targeting SOCS1 and STAT3, PLoS One. 8 (2013) e56395.

[38] E. Brognara, E. Fabbri, G. Montagner, J. Gasparello, A. Manicardi, R. Corradini et al, High levels of apoptosis are induced in human glioma cell lines by co-administration of peptide nucleic acids targeting miR-221 and miR-222, Int J Oncol. 48 (2016) 1029-1038.

[39] S. Ottosen, T.B. Parsley, L. Yang, K. Zeh, L.-J. van Doorn, E. van der Deer et al, In vitro antiviral activity and preclinical and clinical resistance profile of Miravirsen, a novel antihepatitis $\mathrm{C}$ virus therapeutic targeting the human factor miR-122, Antimicrob Agents Chemother. 59 (2015) 599-608.

[40] Regulus Therapeutics Inc. Clinical pipeline of RG-101. Online. 2016. Available from URL: http://regulusrx.com/programs/clinical-pipeline/rg-101/

[41] M.A. Zenkova, Artificial Nucleases, Nucleic Acids and Molecular Biology. 13 (2004).

[42] N.G. Beloglazova, V.N. Sil'nikov, M.A. Zenkova, V.V. Vlassov, Cleavage of yeast tRNAPhe with complementary oligonucleotide conjugated to a small ribonuclease mimic, FEBS Lett. 481 (2000) 277-280. 
[43] H. Inoue, T. Furukawa, T. Tamura, Y. Komatsu, E. Ohtsuka, Two-terpyridine Cu(II) complexes-containing antisense systems for rapid and highly site-specific RNA cleavage, Nucleic Acids Symp Ser. 44 (2000) 279-280.

[44] N.L. Mironova, D.V. Pyshnyi, E.M. Ivanova, V.F. Zarytova, M.A. Zenkova, H.J. Gross et al, Sequence-specific cleavage of the target RNA with oligonucleotide-peptide conjugates, Russ Chem Bull. 51 (2002) 177-1186.

[45] N.G. Beloglazova, M.M. Fabani, M.A. Zenkova, E.V. Bichenkova, N.N. Polushin, V.V. Sil'nikov et al, Sequence-specific artificial ribonucleases. I. Bis-imidazole-containing oligonucleotide conjugates prepared using precursor-based strategy, Nucleic Acids Res. 32 (2004) 3887-3897.

[46] C. Gnaccarini, S. Peter, U. Scheffer, S. Vonhoff, S. Klussmann, M.W. Göbel, Site-specific cleavage of RNA by a metal-free artificial nuclease attached to antisense oligonucleotides, J Am Chem Soc. 128 (2006) 8063-8067.

[47] N.G. Beloglazova, M.M. Fabani, N.N. Polushin, V.V. Sil'nikov, V.V. Vlassov, E.V. Bichenkova et al, Site-selective artificial ribonucleases: oligonucleotide conjugates containing multiple imidazole residues in the catalytic domain, J Nucleic Acids. 2011 (2011) 748632.

[48] H. Takayama, S. Sakamoto, M. Kitamura, H. Inoue, Development of site-specific artificial ribonucleases, Nucleic Acids Symp Ser (Oxf). 51 (2007) 203-204.

[49] F. Danneberg, A. Ghidini, P. Dogandzhiyski, E. Kalden, R. Strömberg, M.W. Göbel, Sequence-specific RNA cleavage by PNA conjugates of the metal-free artificial ribonuclease tris(2-aminobenzimidazole), Beilstein J Org Chem. 11 (2015) 493-498.

[50] A. Williams, Y. Staroseletz, M.A. Zenkova, L. Jeannin, H. Aojula, E.V. Bichenkova, Peptidyl-oligonucleotide conjugates demonstrate efficient cleavage of RNA in a sequencespecific manner, Bioconjug Chem. 26 (2015) 1129-1143.

[51] Y. Staroseletz, A. Williams, K.K. Burusco, I. Alibay, V.V. Vlassov, M.A. Zenkova et al, 'Dual' peptidyl-oligonucleotide conjugates: role of conformational flexibility in catalytic cleavage of RNA, Biomaterials 112 (2017) 44-61.

[52] Y. Aiba, T. Lönnberg, M. Komiyama, Manipulation of Single-Stranded DNA by Using an Artificial Site-Selective DNA Cutter Composed of Cerium(IV)/EDTA and PhosphonateOligonucleotide Conjugates, Chem Asian J. 6 (2011) 2407-2411.

[53] T. Niittymaki, H. Lönnberg, Artificial ribonucleases, Org. Biomol. Chem. 4 (2006) 15-25.

[54] H. Lönnberg, Cleavage of RNA phosphodiester bonds by small molecular entities: a mechanistic insight, Org. Biomol. Chem. 9 (2011) 1687-1703.

[55] F. Silberklang, A.M. Gillum, U.L. RajBhandary, Use of in vitro 32P-labeling in the sequence analysis of nonradioactive tRNAs, Methods Enzymol. 59 (1979) 58-109. 
[56] A.V. Vlasov, V.V. Vlasov, R. Giege, RNA hydrolysis catalyzed by imidazole as a reaction for studying the secondary structure of RNA and complexes of RNA with oligonucleotides, Dokl. Akad. Nauk. 349 (1996) 411-413.

[57] H. Donis-Keller, A.M. Maxam, W. Gilbert, Mapping adenines, guanines and pyrimidines in RNA, Nucleic Acids Res. 4 (1977) 2527-2538.

[58] D.A. Case, J.T. Berryman, R.M. Betz, D.S. Cerutti, T.E. Cheatham, T.A. Darden et al, (2015) AMBER 2015, University of California, San Francisco.

[59] Molecular Operating Environment (MOE), 2014.09; (2014) Chemical Computing Group Inc., 1010 Sherbooke St. West, Suite \#910, Montreal, QC, Canada, H3A 2R7.

[60] G.P.H. Santini, J.A.H. Cognet, D.Xu, K.K. Singarapu, C. Hervé du Penhoat, Nucleic acid folding determined by mesoscale modeling and NMR spectroscopy: solution structure of d(GCGAAAGC), J Phys Chem B. 113 (2009) 6881-6893.

[61] N. Guex, M.C. Peitsch, T. Schwede, Automated comparative protein structure modeling with SWISS-MODEL and Swiss-PdbViewer: a historical perspective, Electrophoresis. 30 (2009) 162-173.

[62] H. Nguyen, D.R. Roe, C. Simmerling, Improved Generalized Born Solvent Model Parameters for Protein Simulations, J Chem Theory Comput. 9 (2013)2020-2034.

[63] J. Wang, R.M. Wolf, J.W. Caldwell, P.A. Kollamn, D.A. Case, Development and testing of a general Amber force field, J. Comput. Chem. 25 (2004) 1157-1174.

[64] A. Onufriev, D. Bashford, D.A. Case, Exploring protein native states and large-scale conformational changes with a modified generalized born model, Proteins. 55 (2004) 383-394.

[65] J.P. Ryckaert, G. Ciccotti, H.J.C. Berendsen, Numerical integration of the cartesian equations of motion of a system with constraints: molecular dynamics of n-alkanes, J. Comput. Phys. 23 (1977) 327-341.

[66] C. Chen, D.A. Ridzon, A.J. Broomer, Z. Zhou, D.H. Lee, J.T. Nguyen et al, Real-time quantification of microRNAs by stem-loop RT-PCR, Nucleic Acids Res. 33 (2005) e179.

[67] E. Varkonyi-Gasic, R. Wu, M. Wood, E.F. Walton, R.P. Hellens, Protocol: a highly sensitive RT-PCR method for detection and quantification of microRNAs, Plant Methods. 3 (2007) 12.

[68] N. Mironova, O. Patutina, E. Brenner, A. Kurilshikov,V. Vlassov, M. Zenkova, MicroRNA drop in the bloodstream and microRNA boost in the tumour caused by treatment with ribonuclease A leads to an attenuation of tumour malignancy, Plos One. 8 (2013) e83482.

[69] J.G. Park, B.S. Kramer, S.M. Steinberg, J. Carmichael, J.M. Collins, J.D. Minna et al, Chemosensitivity testing of human colorectal carcinoma cell lines using a tetrazolium-based colorimetric assay, Cancer Res. 47 (1987) 5875-5879. 
[70] O.A. Patutina, N.L. Mironova, N.A. Popova, V.I. Kaledin, V.P. Nikolin, V.V. Vlassov et al, The siRNA targeted to mdrlb and mdrla mRNAs in vivo sensitizes murine lymphosarcoma to chemotherapy, BMC Cancer. 10 (2010) 204-215.

[71] S.D. Selcuklu, M.T. Donoghue, C. Spillane, miR-21 as a key regulator of oncogenic processes, Biochem Soc Trans. 37 (2009) 918-925.

[72] L.E. Buscaglia, Y. Li, Apoptosis and the target genes of microRNA-21, Chin J Cancer. 30 (2011) 371-380.

[73] S. Li, Z. Liang, L. Xu, F. Zou, MicroRNA-21: a ubiquitously expressed pro-survival factor in cancer and other diseases, Mol Cell Biochem. 360 (2012) 147-158.

[74] Y. Huang, Y.B. Yang, X.H. Zhang, X.L. Yu, Z.B. Wang, X.C. Cheng, MicroRNA-21 gene and cancer, Med Oncol. 30 (2013) 376-385.

[75] T. Sunami, J. Kondo, I. Hirao, K. Watanabe, K.I. Miura, A. Takénaka, Structure of $\mathrm{d}($ GCGAAAGC) (hexagonal form): a base-intercalated duplex as a stable structure, Acta Crystallogr D Biol Crystallogr. 60 (2004) 90-96.

[76] N.L. Mironova, D.V. Pyshnyi, D.V. Stadler, I.V. Prokudin, Y.I. Boutorine, E.M. Ivanova et al, G-specific RNA-cleaving conjugates of short peptides and oligodeoxyribonucleotides, J Biomol Struct Dyn. 23 (2006) 591-602.

[77] N.L. Mironova, D.V. Pyshnyi, D.V. Shtadler, A.A. Fedorova, V.V. Vlassov, M.A. Zenkova, RNase T1 mimicking artificial ribonuclease, Nucleic Acids Res. 35 (2007) 2356-2367.

[78] G.A. Soukup, R.R. Breaker, Relationship between internucleotide linkage geometry and the stability of RNA, RNA. 5 (1999) 1308-1325.

[79] R. Geney, M. Layten, R. Gomperts, V. Hornak, C. J. Simmerling, Investigation of Salt Bridge Stability in a Generalized Born Solvent Model, Chem. Theory Comput. 2 (2005) 115127.

[80] N. Mironova, O. Shklyaeva, E. Andreeva, N. Popova, V. Kaledin, V. Nikolin et al, Animal model of drug-resistant tumor progression, Ann N Y Acad Sci. 1091 (2006) 490-500.

[81] L.Canaple, D. Hüsken, J. Hall, R. Häner, Artificial ribonucleases: efficient and specific in vitro cleavage of human c-raf-1 RNA, Bioconjug Chem. 13 (2002) 945-951.

[82] A. Kuzuya, R. Mizoguchi, F. Morisawa, M. Komiyama, Novel approach for SNP genotyping based on site-selective RNA scission, Nucleic Acids Res Suppl. 2 (2002) 129-130.

[83] B.F. Baker, S.S. Lot, J. Kringel, S. Cheng-Flournoy, P. Villiet, H.M. Sasmor et al, Oligonucleotide-europium complex conjugate designed to cleave the 5' cap structure of the ICAM-1 transcript potentiates antisense activity in cells, Nucleic Acids Res. 27 (1999) 15471551. 
[84] K. Ushijima, M. Shirakawa, K. Kagoshima, W.S. Park, N. Miyano-Kurosaki, H. Takaku, Anti-HIV-1 activity of an antisense phosphorothioate oligonucleotide bearing imidazole and primary amine groups, Bioorg Med Chem. 9 (2001) 2165-2169.

[85] M. Gaglione, G. Milano, A. Chambery, L. Moggio, A. Romanelli, A. Messere, PNA-based artificial nucleases as antisense and anti-miRNA oligonucleotide agents, Mol Biosyst. 7 (2011) 2490-2499.

[86] J.E. Lee, E. Bae, C.A. Bingman, G.N.Jr Phillips, R.T. Raines, Structural basis for catalysis by onconase, J Mol Biol. 375 (2008) 165-177.

[87] B. Burke, S. An, K. Musier-Forsyth, Functional guanine-arginine interaction between tRNAPro and prolyl-tRNA synthetase that couples binding and catalysis, Biochim Biophys Acta. 1784 (2008) 1222-1225.

[88] F.E. Loughlin, R.E. Mansfield, P.M. Vaz, A.P. McGrath, S. Setiyaputra, R. Gamsjaeger et al, The zinc fingers of the SR-like protein ZRANB2 are single-stranded RNA-binding domains that recognize 5' splice site-like sequences, Proc Natl Acad Sci U S A. 106 (2009) 5581-5586.

[89] H. Hu, Y. Li, J. Gu, X. Zhu, D. Dong, J. Yao et al, Antisense oligonucleotide against miR21 inhibits migration and induces apoptosis in leukemic K562 cells, Leuk Lymphoma. 51 (2010) 694-701.

[90] Z. Lu, M. Liu, V. Stribinskis, C.M. Klinge, K.S. Ramos, N.H. Colburn et al, MicroRNA-21 promotes cell transformation by targeting the programmed cell death 4 gene, Oncogene. 27 (2008) 4373-4379.

[91] Y.J. Tao, Y.J. Li, W. Zheng, J.J. Zhao, M.M. Guo, Y. Zhou et al, Antisense oligonucleotides against microRNA-21 reduced the proliferation and migration of human colon carcinoma cells, Cancer Cell Int. 15 (2015) 77.

[92] S. Zhu, M.L. Si, H. Wu, Y.Y. Mo, MicroRNA-21 targets the tumor suppressor gene tropomyosin 1 (TPM1), J Biol Chem. 282 (2007) 14328-14336. 


\section{FIGURE LEGENDS}

Fig. 1. The structure of anti-miR-21 peptide-oligonucleotide conjugates (POCs). A. Schematic representation of a general structure of anti-miR-21 POCs. Labels '10-16 n', '16 n' or '14-16 n' indicate the length ranges of the antisense 'recognition' sequence used in different conjugates. Label '6-9 n' indicates the length range of the stem. B-C. The chemical structure of the peptide (pep) acetyl-(LeuArg) $)_{2}$-Gly-(LeuArg) $)_{2}-\mathrm{Gly}-\mathrm{COOH}$. The peptide was conjugated via the carboxylic group of the C-terminus to the aminohexyl linker, which was attached to either the 5'or 3'-terminal phosphate of the antisense oligonucleotide (asON) (B and $\mathbf{C}$, respectively). Amino acids are designated by numbers which are used for the interpretation of the data from molecular dynamics simulation.

Fig. 2. Hybridization of oligonucleotides with $5^{\prime}-\left[{ }^{32} \mathrm{P}\right]-\mathrm{miR}-21$ (*miR-21). Autoradiograph of $12 \%$ native PAGE. $*$ miR-21 $(1 \mu \mathrm{M})$ and one of the oligonucleotides $(1 \mu \mathrm{M})$ were incubated at $37^{\circ} \mathrm{C}$ for $1 \mathrm{~h}$. The samples were loaded onto the running gel immediately after quenching of the reaction with an interval of $2 \mathrm{~min}$.

Fig. 3. Hybridization of POCs and corresponding addressing oligonucleotides with *miR-21. A. Autoradiograph of $12 \%$ native PAGE. *miR-21 $(1 \mu \mathrm{M})$ and conjugates or oligonucleotides (5 $\mu \mathrm{M}$ ) were incubated at $37^{\circ} \mathrm{C}$ for $20 \mathrm{~min}$. The samples were loaded onto the running gel immediately after quenching of the reaction with an interval of $2 \mathrm{~min}$. B. The concentration dependency of binding of oligonucleotide 5 '- $h-9 / 14$ or conjugate $\mathbf{5}$ '-h-9/14 with miR-21. *miR$21(1 \mu \mathrm{M})$ and oligonucleotide or conjugate in different concentrations were incubated at $37^{\circ} \mathrm{C}$ for $20 \mathrm{~min}$.

Fig. 4. Kinetic and concentration analysis of *miR-21 cleavage by 5'-conjugates. A. Autoradiograph of $18 \%$ polyacrylamide/8 M urea gel. Lanes Im and T1, imidazole ladder and partial RNA digestion with RNase T1, respectively. Control - RNA incubated in the absence of conjugate for 0 and $72 \mathrm{~h}$. * miR-21 $(1 \mu \mathrm{M})$ and $5^{\prime}$-conjugates $(20 \mu \mathrm{M})$ were incubated at $37^{\circ} \mathrm{C}$ for $0-72 \mathrm{~h}$. The conjugate type and incubation time are shown at the top. B. Positions of miR21 cleavage induced by 5'-conjugates 5'-h-6/16 and 5'-h-6/14 (indicated by arrows). C. Kinetics of *miR-21 cleavage by conjugates. *miR-21 $(1 \mu \mathrm{M})$ and one of the conjugates $(20 \mu \mathrm{M})$ were incubated at $37^{\circ} \mathrm{C}$ for $0-72 \mathrm{~h}$. D. Concentration dependence of $*$ miR-21 cleavage at the time point $24 \mathrm{~h} . *$ miR-21 $(1 \mu \mathrm{M})$ and conjugates $(1-50 \mu \mathrm{M})$ were incubated at $37^{\circ} \mathrm{C}$ for $24 \mathrm{~h}$.

Fig. 5. Concentration analysis of miR-21 cleavage by complementary conjugate $\mathbf{5} \cdot \mathbf{- h}-\mathbf{9} / \mathbf{1 4}$ and non-complemantery conjugate 5'-luc-9/14. A. Autoradiograph of $18 \%$ polyacrylamide/8 M urea gel. Lanes Im and T1, imidazole ladder and partial RNA digestion with RNase T1, respectively. 
$\mathrm{C}$ - RNA incubated in the absence of conjugate for $24 \mathrm{~h}$. *miR-21 $(1 \mu \mathrm{M})$ and conjugates $(1-20$ $\mu \mathrm{M})$ were incubated at $37^{\circ} \mathrm{C}$ for $24 \mathrm{~h}$. B. Concentration dependency of *miR-21 cleavage at the time point $24 \mathrm{~h}$.

Fig. 6. Results of the molecular dynamics simulation of the 5'-h-6/14/miR-21 complex. A, B. Structure of 5'-h-6/14 complex with miR-21 after $1 \mu$ s of molecular dynamics simulation in implicit solvent, viewed from two alternative orientations. For 5'-h-6/14, oligonucleotide in white, Leu residues in yellow, Gly in white and Arg by atom type. For miR-21 residues 1-14 in pink; for residues 15-22, Ade in purple, Ura in green and Gua in mauve. The two parts of the system folded together in a compact spherical-like shape at the end of the double helix due to the network of electrostatic interactions involving polar groups in the two parts of the system: salt bridges between the arginine guanidino and RNA phosphate groups, and hydrogen bonds involving arginine side chains, base polar atoms and sugar hydroxyls. C. Distribution of angle $\tau$ over the $1 \mu$ s simulation. D. ${ }^{\prime}{ }^{\prime}\left[\mathrm{G}_{15}\right] \cdots \mathrm{P}\left[\mathrm{A}_{16}\right]$ distance $d$ over the $1 \mu$ s simulation.

Fig. 7. Biological activity of the conjugate 5'-h-9/14 in RLS 40 lymphosarcoma cells. Expression level of miR-21 (A) and let7-g (B) in $\mathrm{RLS}_{40}$ cells after transfection with $1 \mu \mathrm{M}$ of antisense oligonucleotide 5'-h-9/14, control conjugate luc-h-9/14 and anti-miR-21 conjugate 5'-h-9/14. Transfection was performed using Lipofectamine 2000. LF - RLS $_{40}$ cells incubated with Lipofectamine 2000 only. The expression of miRNAs was normalized to U6 and Rpl30. C. Western blot analysis of PDCD4 $48 \mathrm{~h}$ after transfection. GAPDH served as an internal control. 1 - intact $\mathrm{RLS}_{40}$ cell; 2 - RLS 40 cells incubated with Lipofectamine 2000; 3, 4, 5 - RLS 40 cells incubated with $1 \mu \mathrm{M}$ control conjugate luc-h-9/14, antisense oligonucleotide 5' $h-9 / 14$, and antimiR-21 conjugate 5'-h-9/14, respectively. D. The bar graph shows the semi-quantitative analysis of the western blot results for PDCD4. E. Proliferative potential of $\mathrm{RLS}_{40}$ cells $72 \mathrm{~h}$ after transfection with $1 \mu \mathrm{M}$ of antisense oligonucleotide 5'- $h-9 / 14$, control conjugate luc-h-9/14 and anti-miR-21 conjugate 5'-h-9/14. Data are given as medians calculated from three independent experiments. 
Table 1. Oligodeoxyribonucleotides used in the study: sequences and nomenclature.

\begin{tabular}{|c|l|}
\hline Name & \multicolumn{1}{|c|}{ Oligodeoxyribonucleotide sequence $\left(5^{\prime} \rightarrow 3^{\prime}\right)$} \\
\hline $3^{\prime}-16$ & TCAACATCAGTCTGAT \\
\hline $5^{\prime}-14$ & TCAGTCTGATAAGC \\
\hline $5^{\prime}-16$ & TCAGTCTGATAAGCTA \\
\hline $5^{\prime}-h-6 / 10$ & TGATAAGCTAGTCAGCGAAAGCTGAC \\
\hline $5^{\prime}-h-9 / 10$ & TGATAAGCTACAAGTCAGCGAAAGCTGACTTG \\
\hline $5^{\prime}-h-6 / 12$ & TCTGATAAGCTAGTCAGCGAAAGCTGAC \\
\hline $5^{\prime}-h-9 / 12$ & TCTGATAAGCTACAAGTCAGCGAAAGCTGACTTG \\
\hline $5^{\prime}-h-6 / 14$ & AGTCTGATAAGCTAGTCAGCGAAAGCTGAC \\
\hline $5^{\prime}-h-9 / 14$ & AGTCTGATAAGCTACAAGTCAGCGAAAGCTGACTTG \\
\hline $5^{\prime}-h-6 / 16$ & TCAGTCTGATAAGCTAGTCAGCGAAAGCTGAC \\
\hline $5^{\prime}-h-9 / 16$ & TCAGTCTGATAAGCTACAAGTCAGCGAAAGCTGACTTG \\
\hline $3^{\prime}-h-6 / 16$ & $\underline{\text { GTCAGCGAAAGCTGACTCAACATCAGTCTGAT }}$ \\
\hline $3^{\prime}-h-9 / 16$ & $\underline{\text { CAAGTCAGCGAAAGCTGACTTGTCAACATCAGTCTGAT }}$ \\
\hline $3^{\prime}-h-9 / 10$ & $\underline{\text { CAAGTCAGCGAAAGCTGACTTGTCAACATCAG }}$ \\
\hline $5^{\prime}-l u c-h-9 / 14$ & CGATAAATAACGCGCAAGTCAGCGAAAGCTGACTTG \\
\hline
\end{tabular}

Regular font - sequence complementary to miR-21; underlined font - a hairpin. Oligonucleotides were designated as follows: 3'- or 5' indicates the end of oligonucleotide used further for conjugation with a peptide; $h$ indicates the presence of a hairpin in the structure; 6 or 9 indicates the length of the stem; and the labels from 10 to 16 indicate the length of the antisense sequence complementary to miR-21. In the text the names of oligonucleotides are shown in italic and synthesized conjugates have the same nomenclature as corresponding oligonucleotides, but shown in bold. 
A

Catalytic group at the 5'-end of asON Catalytic group at the 3'-end of asON
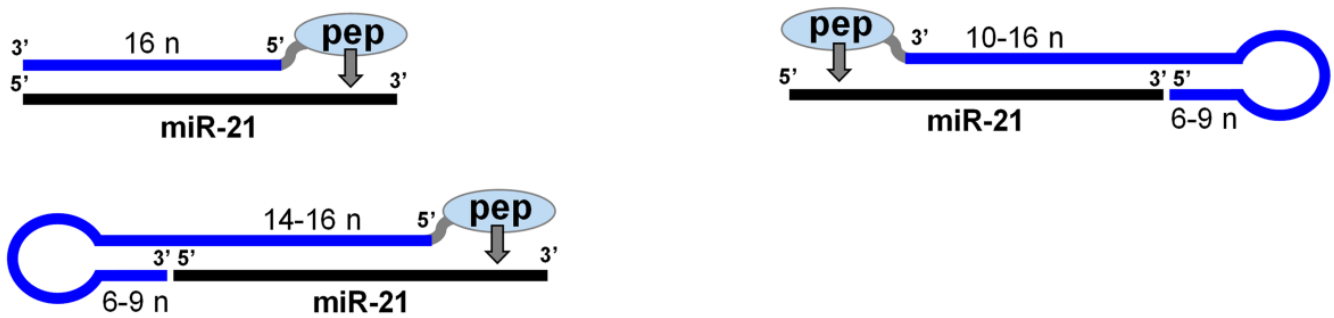

B

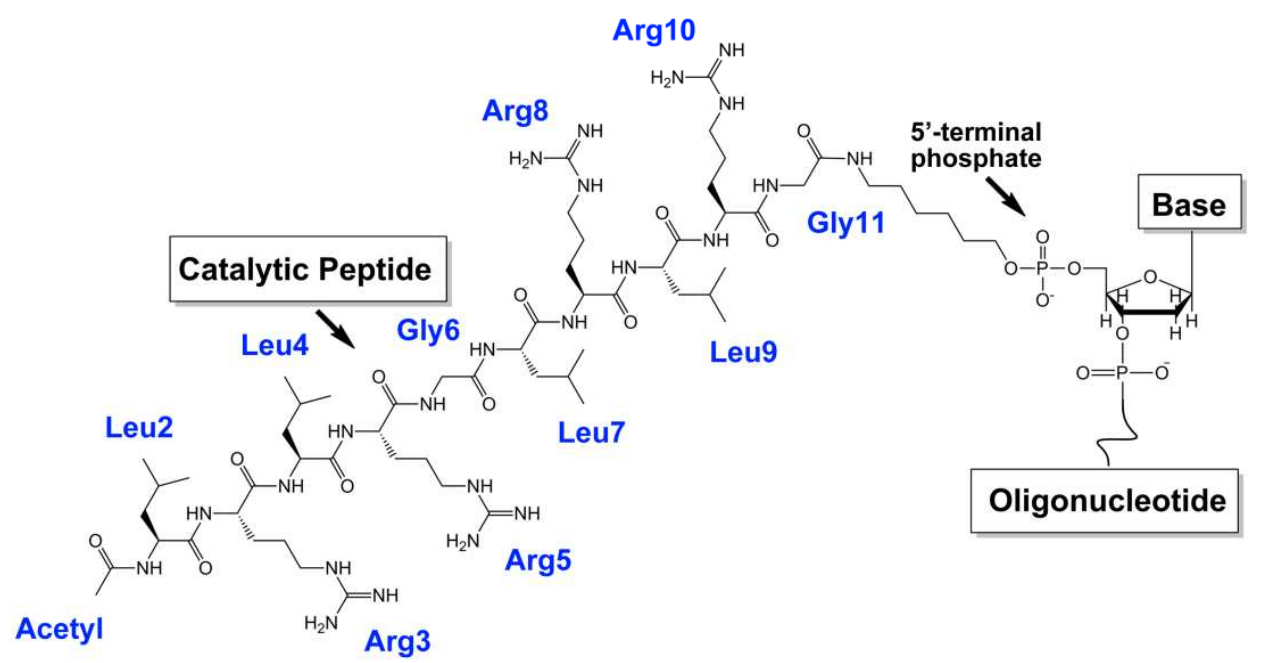

C

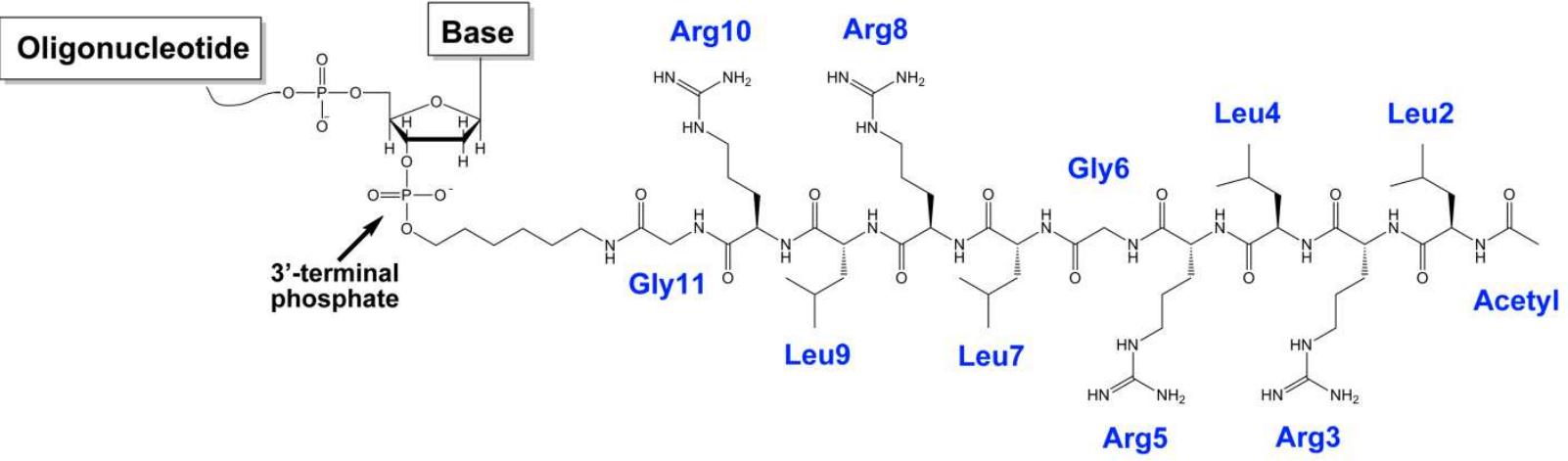

Fig. 1. The structure of anti-miR-21 peptide-oligonucleotide conjugates (POCs). A. Schematic representation of a general structure of anti-miR-21 POCs. Labels '10-16 n', '16 n' or '14-16 n' indicate the length ranges of the antisense 'recognition' sequence used in different conjugates. Label '6-9 n' indicates the length range of the stem. B-C. The chemical structure of the peptide (pep) acetyl-(LeuArg) $)_{2}$-Gly-(LeuArg) $)_{2}-\mathrm{Gly}-\mathrm{COOH}$. The peptide was conjugated via the carboxylic group of the C-terminus to the aminohexyl linker, which was attached to either the 5'or 3'-terminal phosphate of the antisense oligonucleotide (asON) ( $\mathbf{B}$ and $\mathbf{C}$, respectively). Amino acids are designated by numbers which are used for the interpretation of the data from molecular dynamics simulation. 


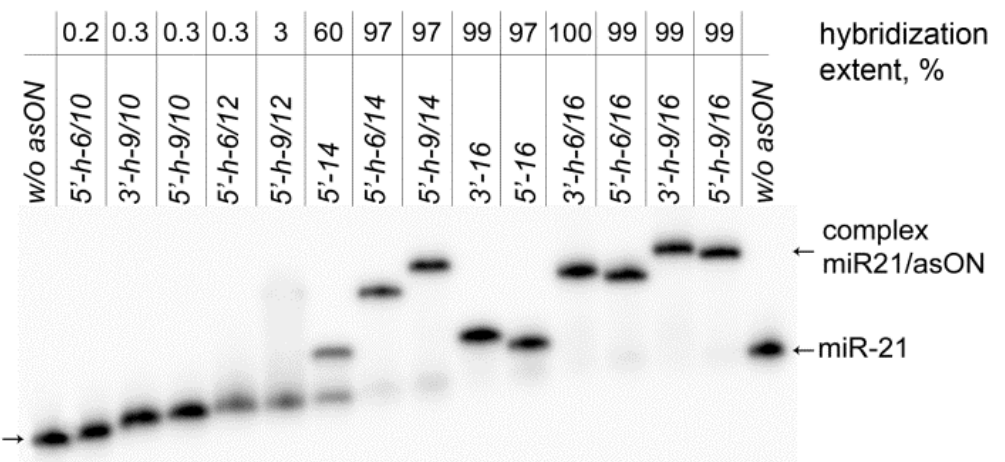

Fig. 2. Hybridization of oligonucleotides with $5^{\prime}-\left[{ }^{32} \mathrm{P}\right]-\mathrm{miR}-21$ (*miR-21). Autoradiograph of $12 \%$ native PAGE. ${ }^{*} \operatorname{miR}-21(1 \mu \mathrm{M})$ and one of the oligonucleotides $(1 \mu \mathrm{M})$ were incubated at $37^{\circ} \mathrm{C}$ for $1 \mathrm{~h}$. The samples were loaded onto the running gel immediately after quenching of the reaction with an interval of $2 \mathrm{~min}$.
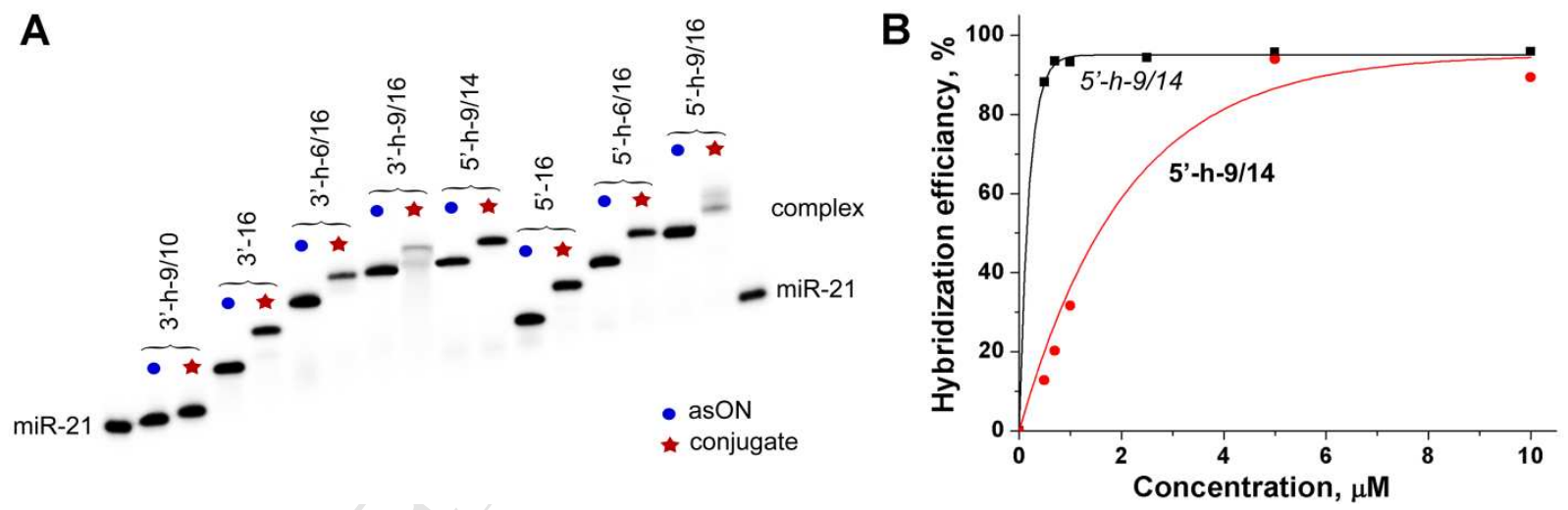

Fig. 3. Hybridization of POCs and corresponding addressing oligonucleotides with *miR-21. A. Autoradiograph of $12 \%$ native PAGE. *miR-21 $(1 \mu \mathrm{M})$ and conjugates or oligonucleotides (5 $\mu \mathrm{M}$ ) were incubated at $37^{\circ} \mathrm{C}$ for $20 \mathrm{~min}$. The samples were loaded onto the running gel immediately after quenching of the reaction with an interval of $2 \mathrm{~min}$. B. The concentration dependency of binding of oligonucleotide 5 '-h-9/14 or conjugate 5'-h-9/14 with miR-21. *miR$21(1 \mu \mathrm{M})$ and oligonucleotide or conjugate in different concentrations were incubated at $37^{\circ} \mathrm{C}$ for $20 \mathrm{~min}$. 

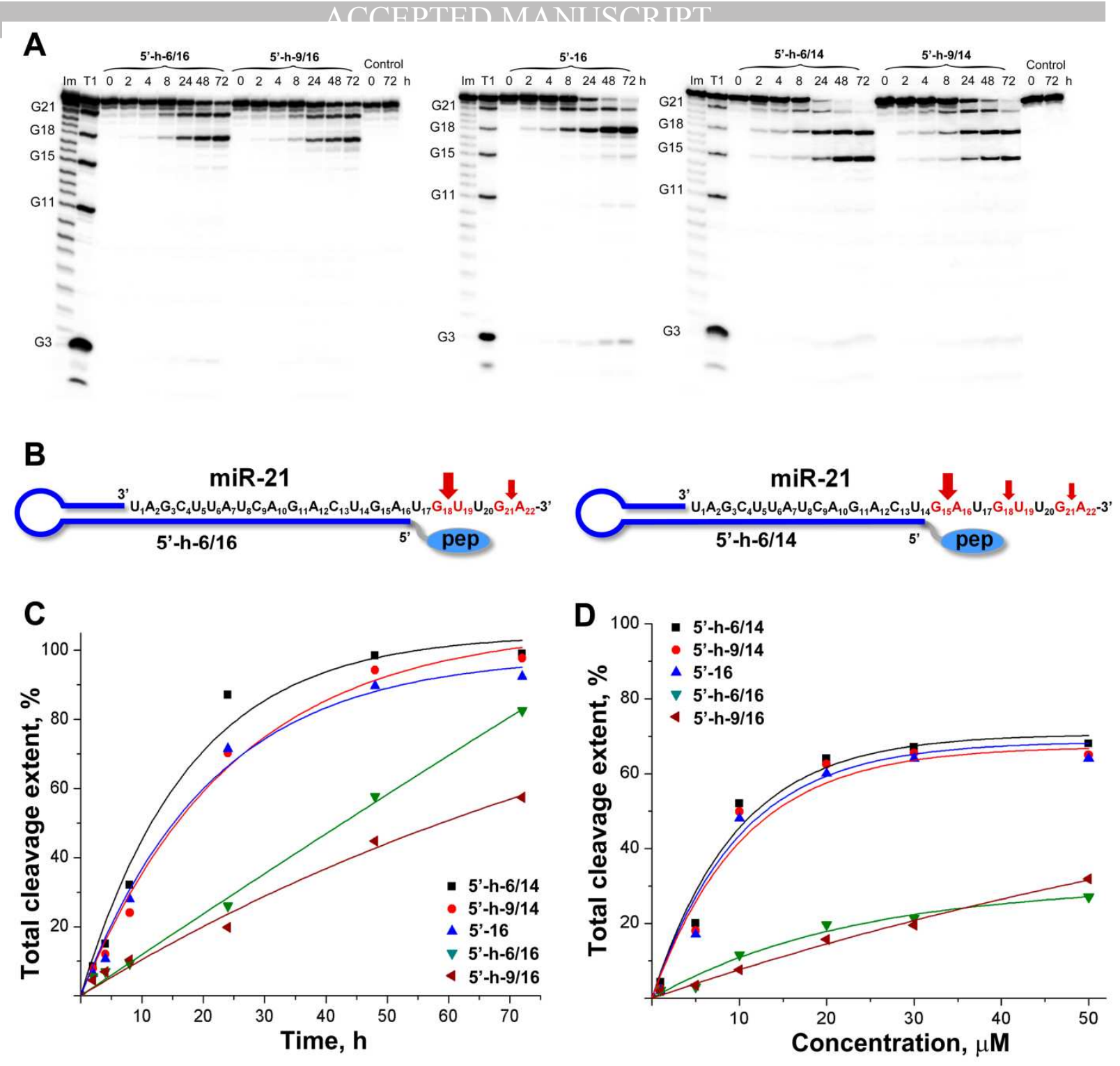

Fig. 4. Kinetic and concentration analysis of *miR-21 cleavage by 5'-conjugates. A. Autoradiograph of $18 \%$ polyacrylamide/ $8 \mathrm{M}$ urea gel. Lanes Im and T1, imidazole ladder and partial RNA digestion with RNase T1, respectively. Control - RNA incubated in the absence of conjugate for 0 and $72 \mathrm{~h}$. ${ }^{*} \mathrm{miR}-21(1 \mu \mathrm{M})$ and $5^{\prime}$-conjugates $(20 \mu \mathrm{M})$ were incubated at $37^{\circ} \mathrm{C}$ for $0-72 \mathrm{~h}$. The conjugate type and incubation time are shown at the top. B. Positions of miR21 cleavage induced by 5'-conjugates 5'-h-6/16 and 5'-h-6/14 (indicated by arrows). C. Kinetics of *miR-21 cleavage by conjugates. *miR-21 $(1 \mu \mathrm{M})$ and one of the conjugates $(20 \mu \mathrm{M})$ were incubated at $37^{\circ} \mathrm{C}$ for $0-72 \mathrm{~h}$. D. Concentration dependence of $*$ miR-21 cleavage at the time point $24 \mathrm{~h}$. *miR-21 $(1 \mu \mathrm{M})$ and conjugates $(1-50 \mu \mathrm{M})$ were incubated at $37^{\circ} \mathrm{C}$ for $24 \mathrm{~h}$. 

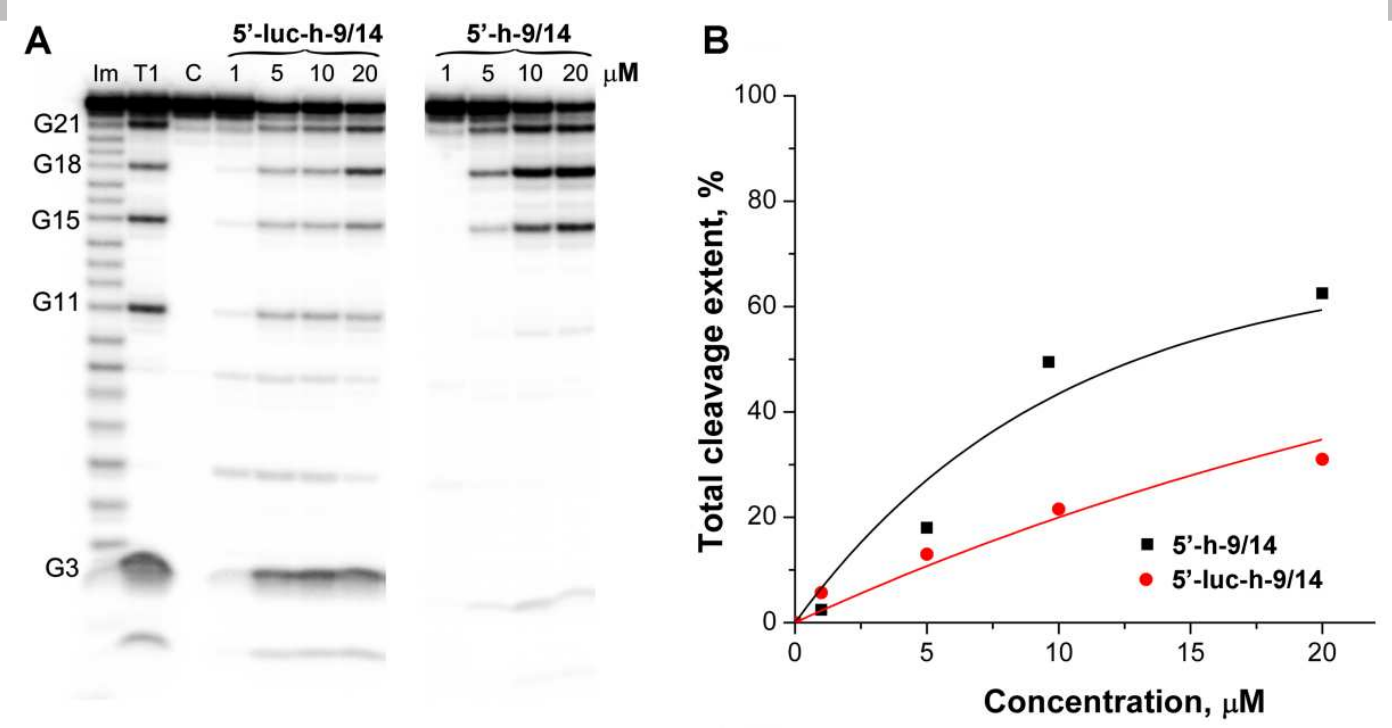

Fig. 5. Concentration analysis of miR-21 cleavage by complementary conjugate $\mathbf{5} \cdot \mathbf{- h}-\mathbf{9} / \mathbf{1 4}$ and non-complemantery conjugate 5'-luc-9/14. A. Autoradiograph of $18 \%$ polyacrylamide/8 M urea gel. Lanes Im and T1, imidazole ladder and partial RNA digestion with RNase T1, respectively. $\mathrm{C}$ - RNA incubated in the absence of conjugate for $24 \mathrm{~h}$. *miR-21 $(1 \mu \mathrm{M})$ and conjugates $(1-20$ $\mu \mathrm{M})$ were incubated at $37^{\circ} \mathrm{C}$ for $24 \mathrm{~h}$. B. Concentration dependency of *miR-21 cleavage at the time point $24 \mathrm{~h}$. 


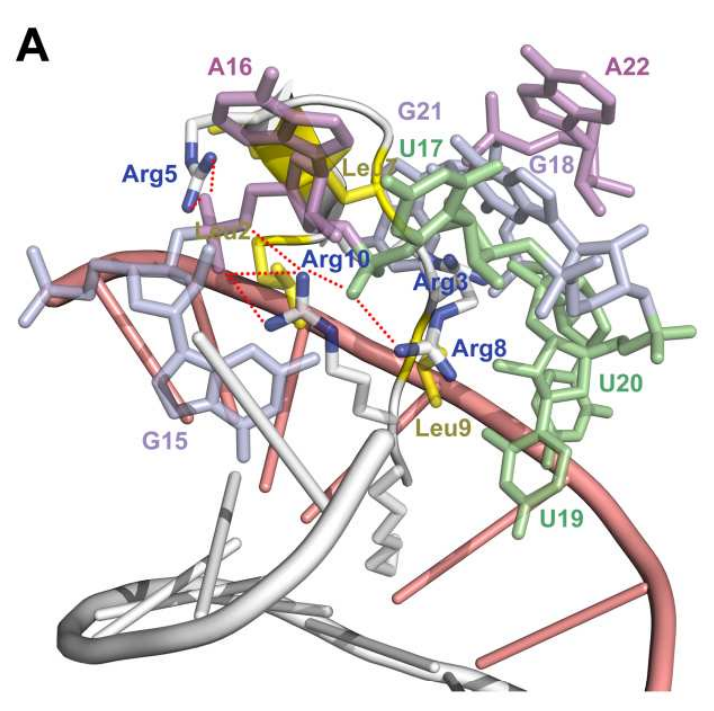

C

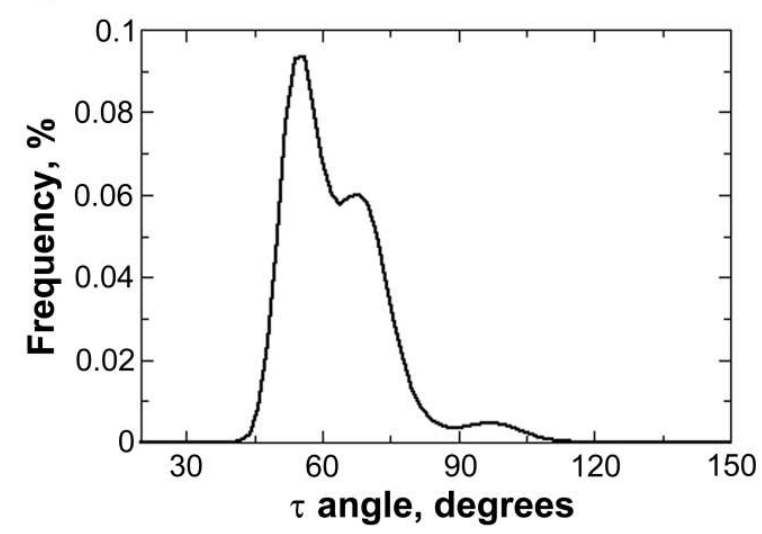

B

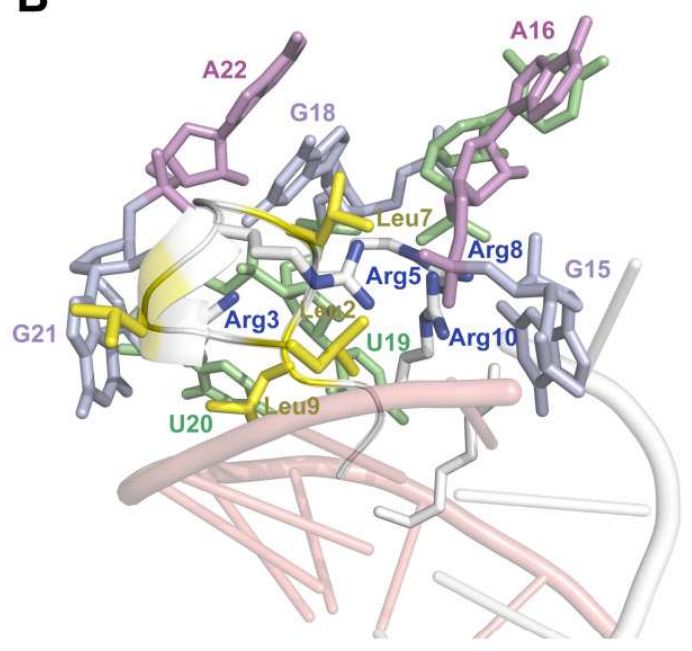

D

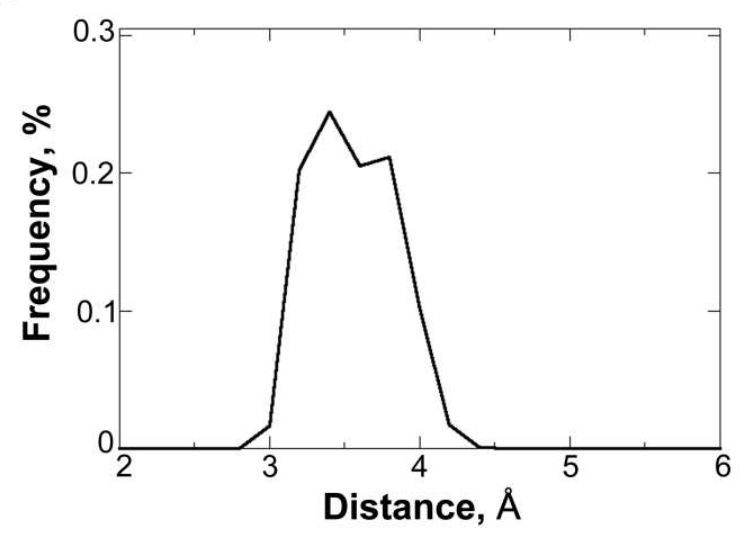

Fig. 6. Results of the molecular dynamics simulation of the 5'-h-6/14/miR-21 complex. A, B. Structure of 5'-h-6/14 complex with miR-21 after $1 \mu$ s of molecular dynamics simulation in implicit solvent, viewed from two alternative orientations. For 5'-h-6/14, oligonucleotide in white, Leu residues in yellow, Gly in white and Arg by atom type. For miR-21 residues 1-14 in pink; for residues 15-22, Ade in purple, Ura in green and Gua in mauve. The two parts of the system folded together in a compact spherical-like shape at the end of the double helix due to the network of electrostatic interactions involving polar groups in the two parts of the system: salt bridges between the arginine guanidino and RNA phosphate groups, and hydrogen bonds involving arginine side chains, base polar atoms and sugar hydroxyls. C. Distribution of angle $\tau$ over the $1 \mu$ s simulation. D. $\mathrm{O}^{\prime}{ }^{\prime}\left[\mathrm{G}_{15}\right] \cdots \mathrm{P}\left[\mathrm{A}_{16}\right]$ distance $d$ over the $1 \mu$ s simulation. 

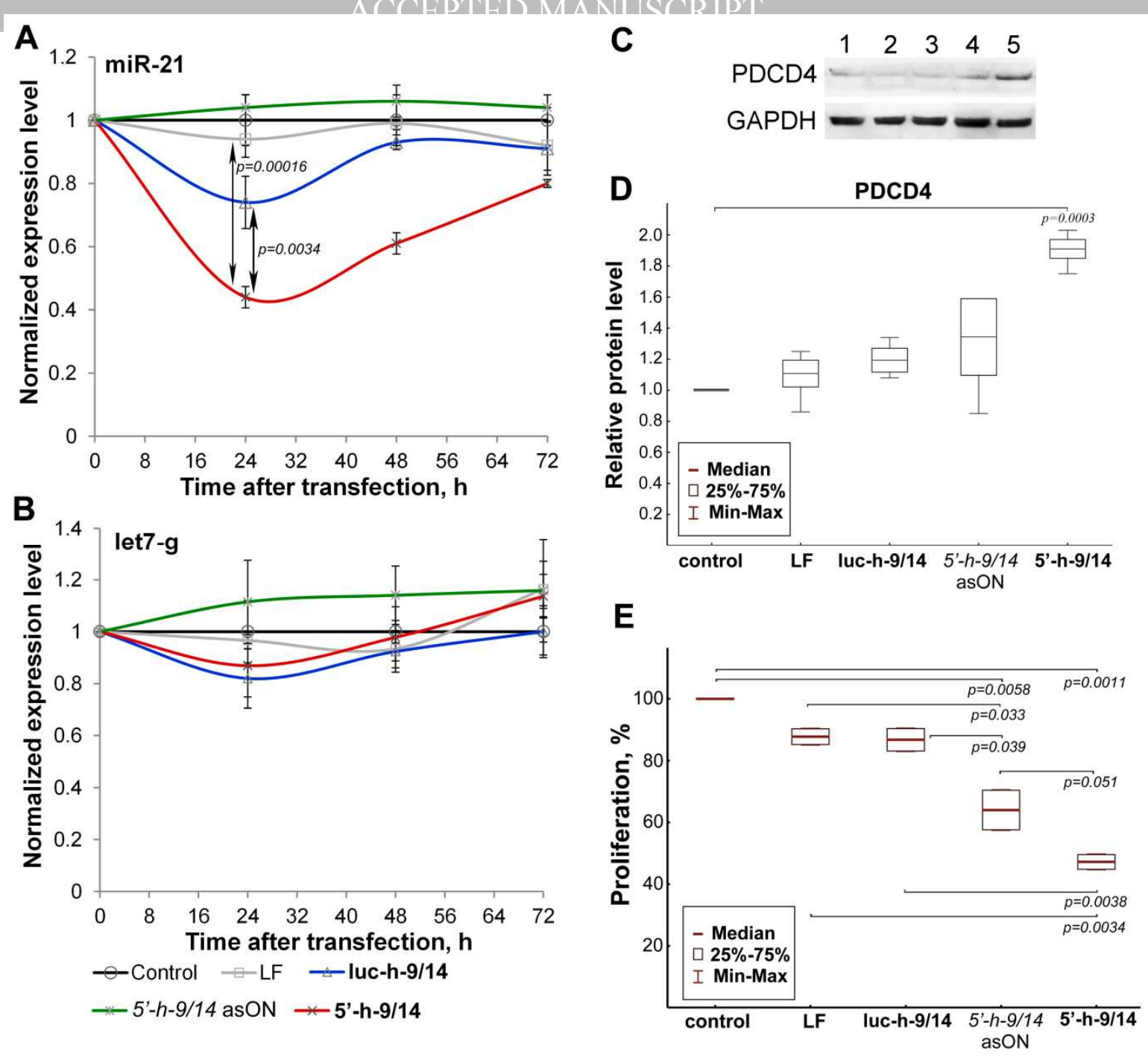

Fig. 7. Biological activity of the conjugate 5'-h-9/14 in $\mathrm{RLS}_{40}$ lymphosarcoma cells. Expression level of miR-21 (A) and let7-g (B) in $\mathrm{RLS}_{40}$ cells after transfection with $1 \mu \mathrm{M}$ of antisense oligonucleotide 5'-h-9/14, control conjugate luc-h-9/14 and anti-miR-21 conjugate 5'-h-9/14. Transfection was performed using Lipofectamine 2000. LF - RLS 40 cells incubated with Lipofectamine 2000 only. The expression of miRNAs was normalized to U6 and Rpl30. C. Western blot analysis of PDCD4 $48 \mathrm{~h}$ after transfection. GAPDH served as an internal control. 1 - intact $\mathrm{RLS}_{40}$ cell; 2 - $\mathrm{RLS}_{40}$ cells incubated with Lipofectamine 2000; 3, 4, 5 - RLS 40 cells incubated with $1 \mu \mathrm{M}$ control conjugate luc-h-9/14, antisense oligonucleotide 5'- $h-9 / 14$, and antimiR-21 conjugate 5'-h-9/14, respectively. D. The bar graph shows the semi-quantitative analysis of the western blot results for PDCD4. E. Proliferative potential of $\mathrm{RLS}_{40}$ cells $72 \mathrm{~h}$ after transfection with $1 \mu \mathrm{M}$ of antisense oligonucleotide 5'-h-9/14, control conjugate luc-h-9/14 and anti-miR-21 conjugate 5'-h-9/14. Data are given as medians calculated from three independent experiments. 
A Catalytic group at the 5'-end of asON Catalytic group at the 3'-end of asON
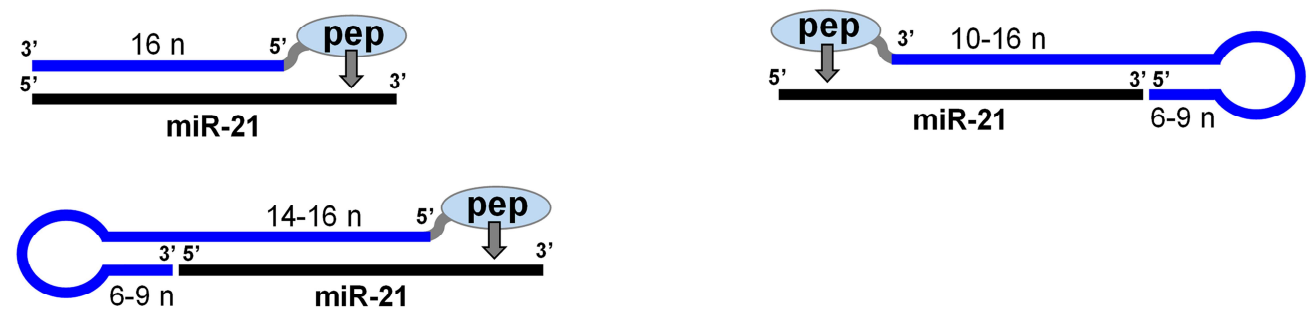

B

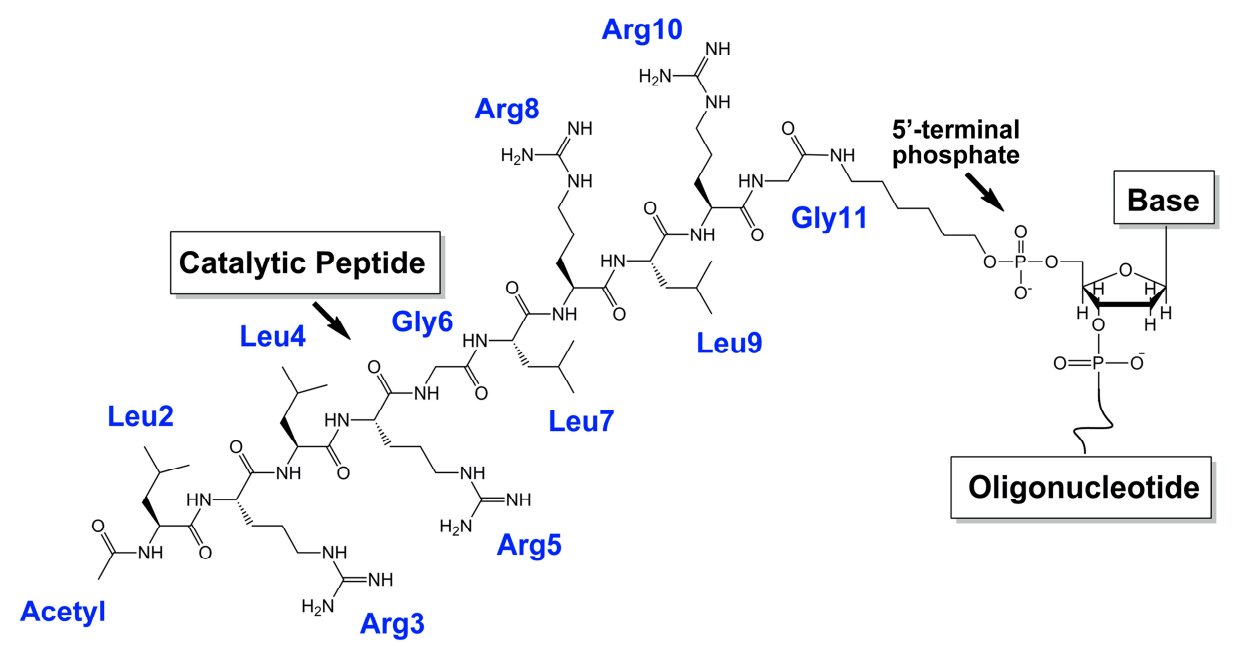

C

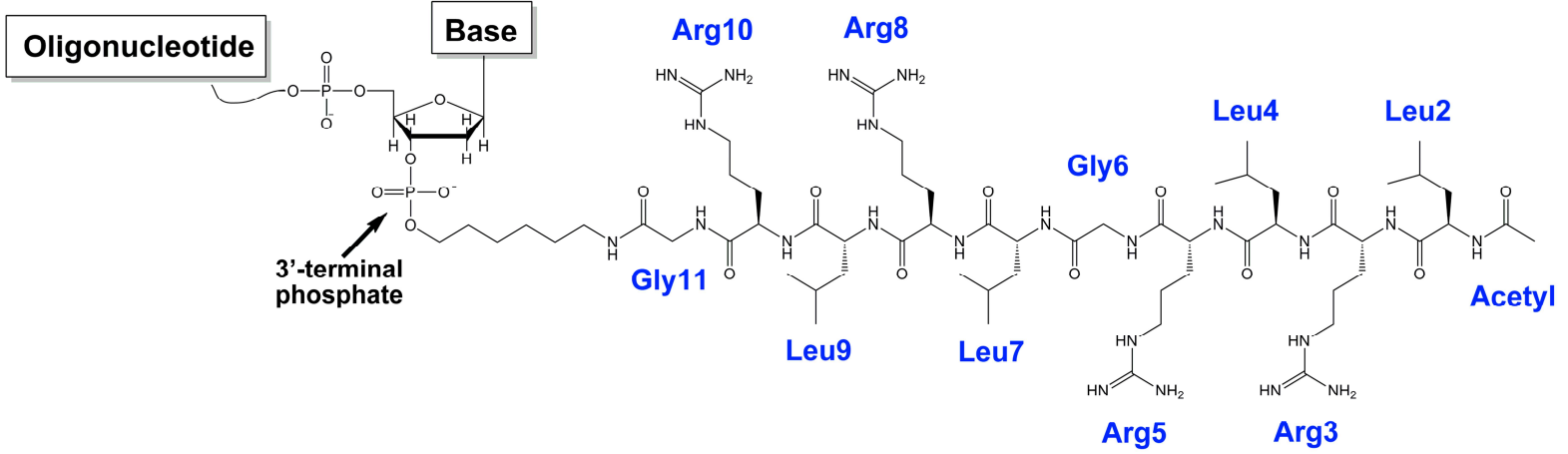




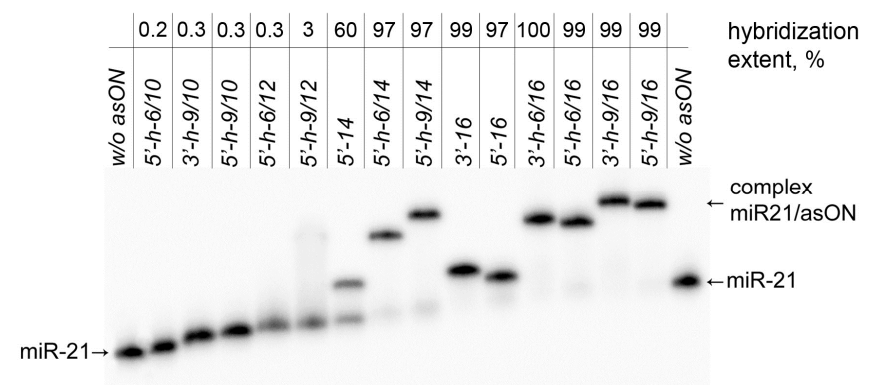



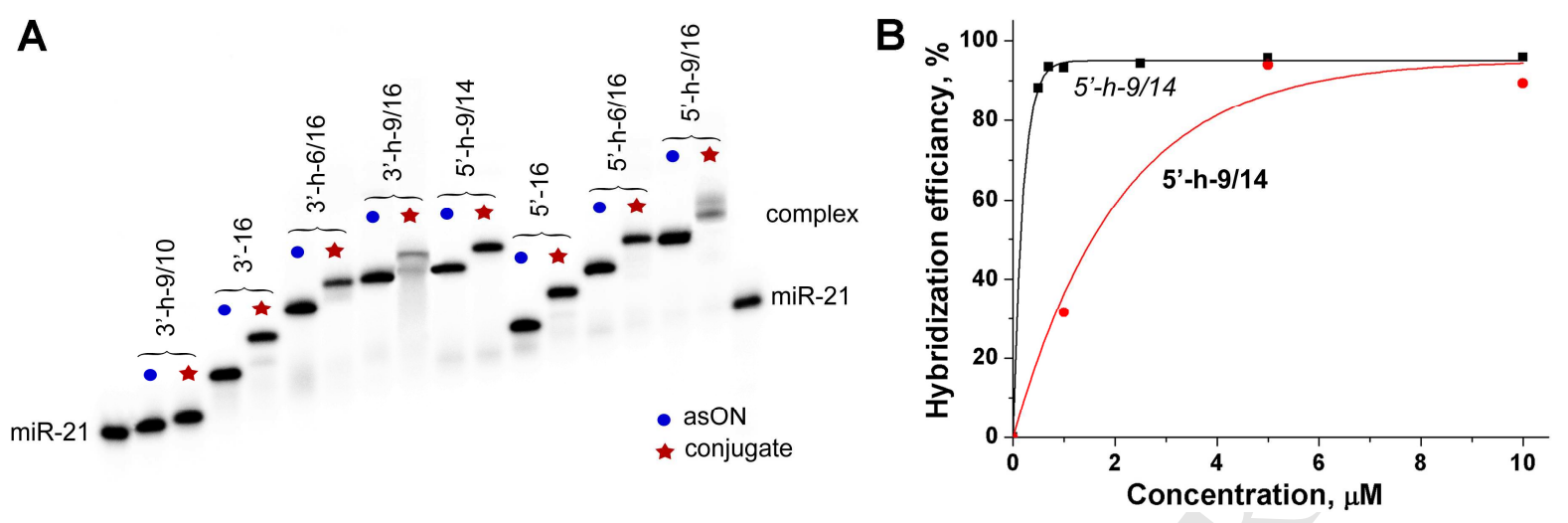
A
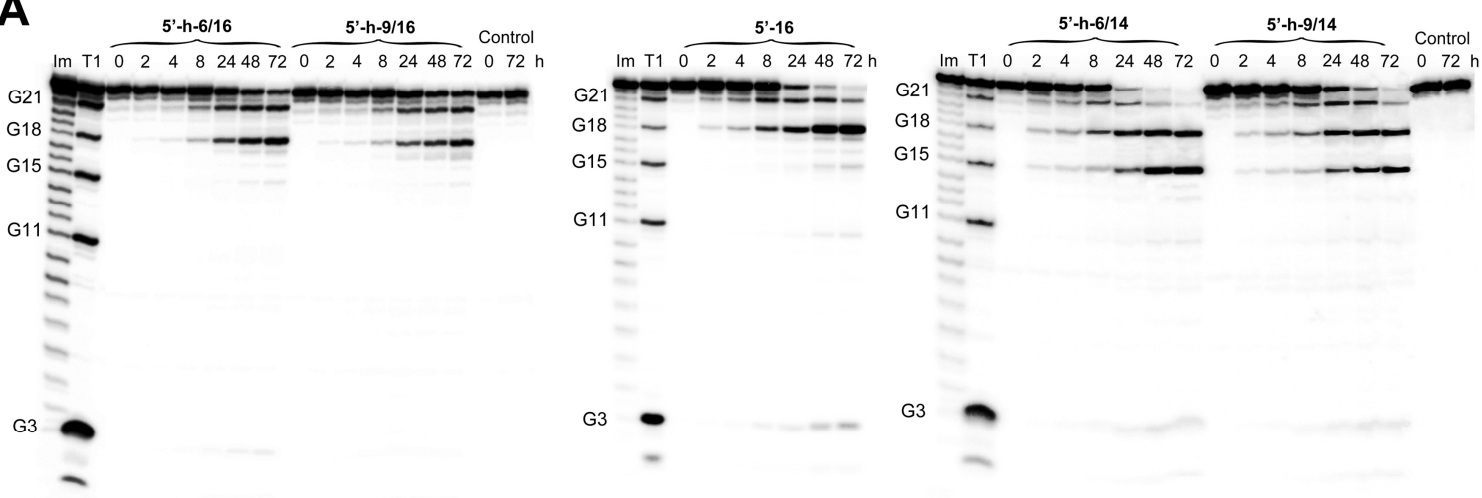

B
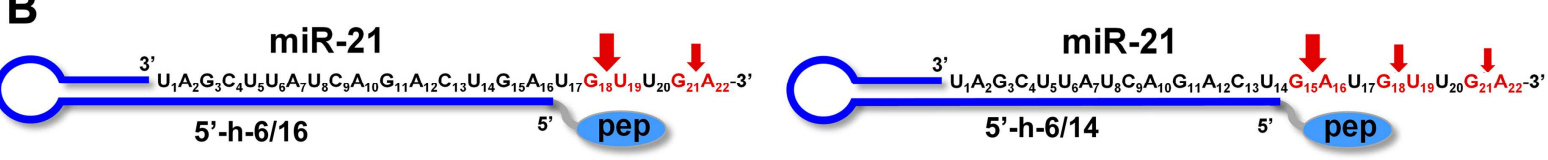

C
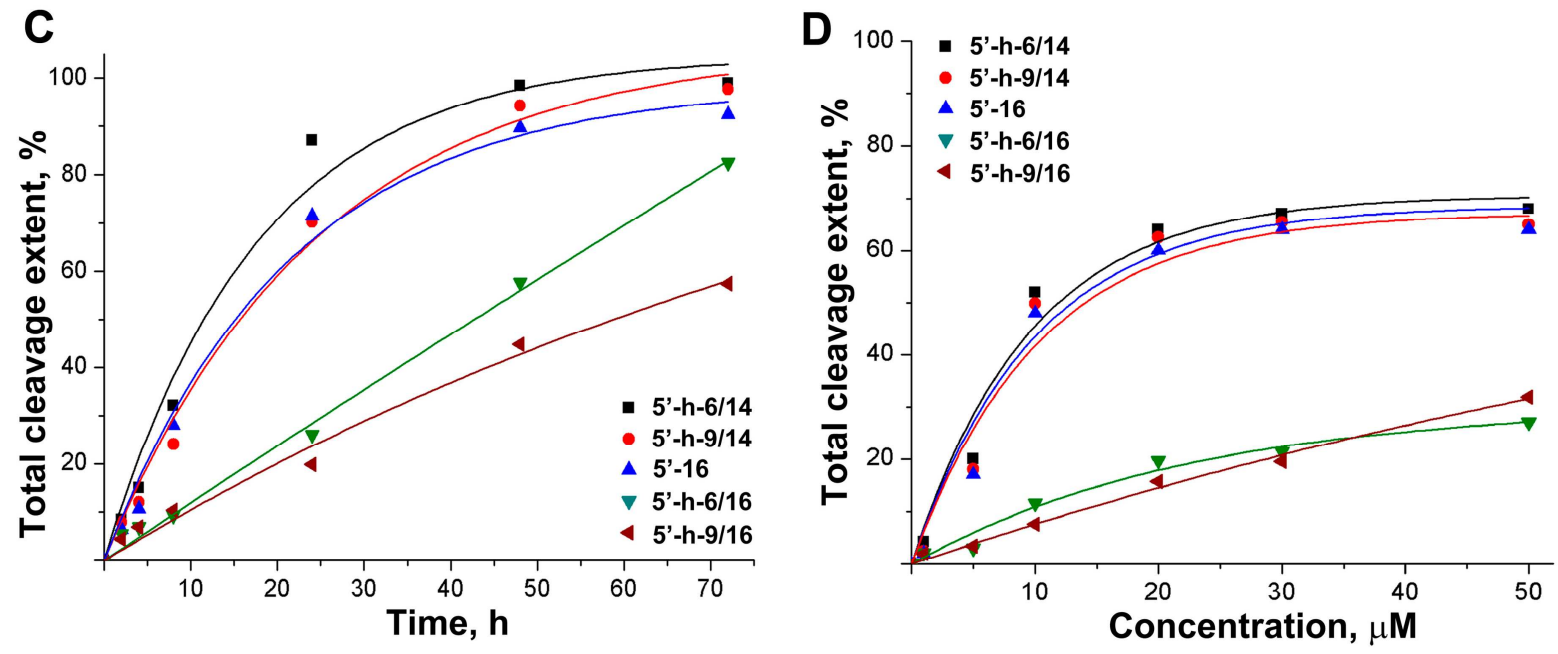


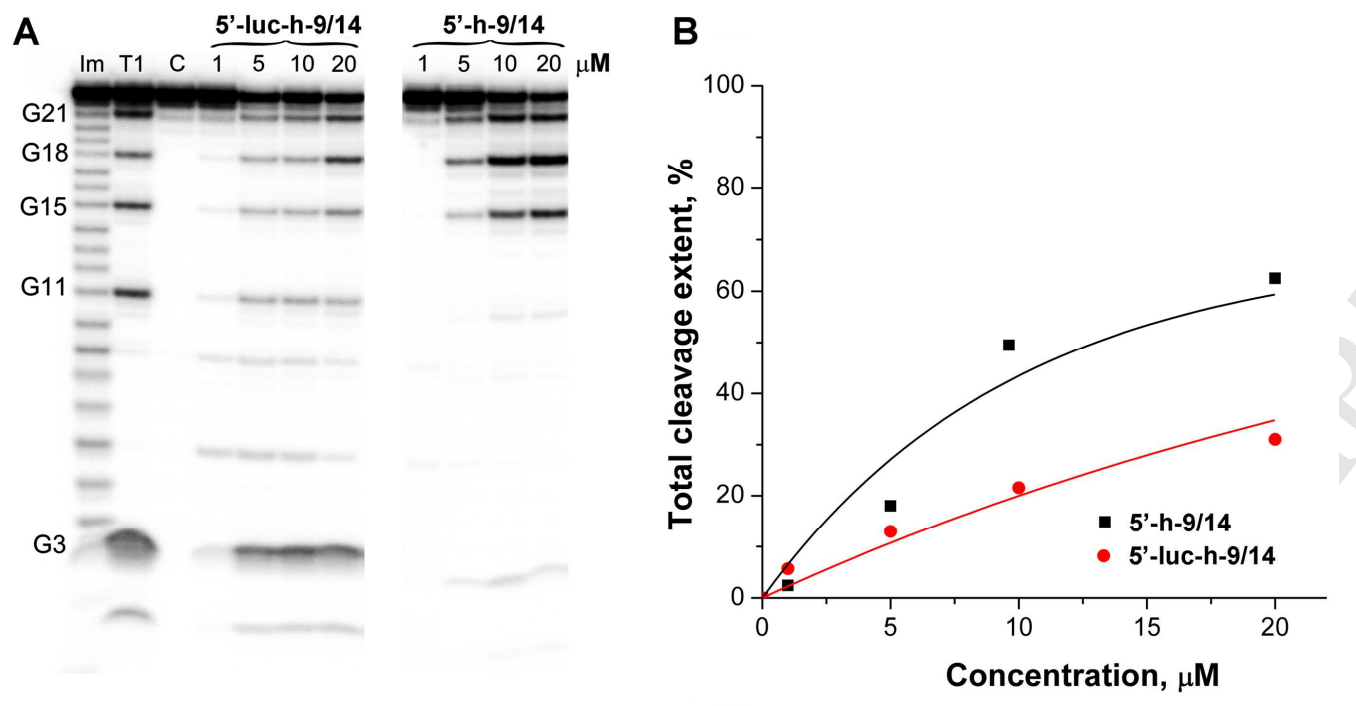


A

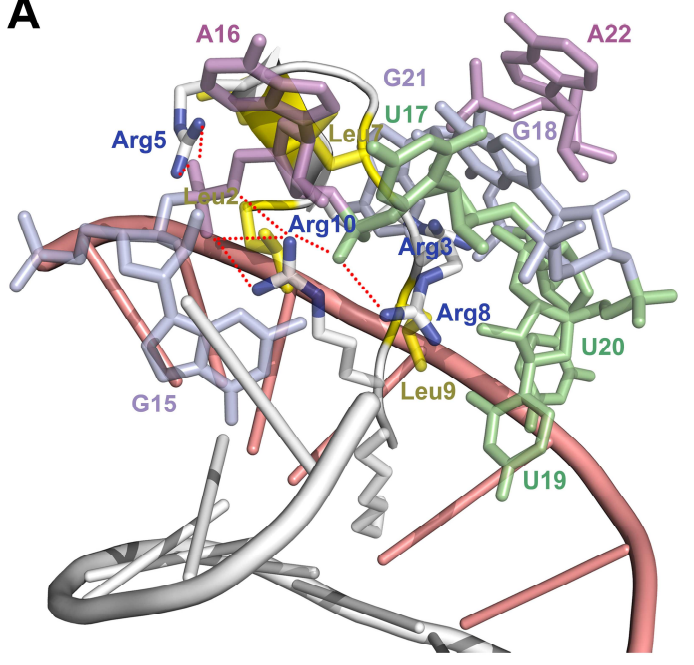

C

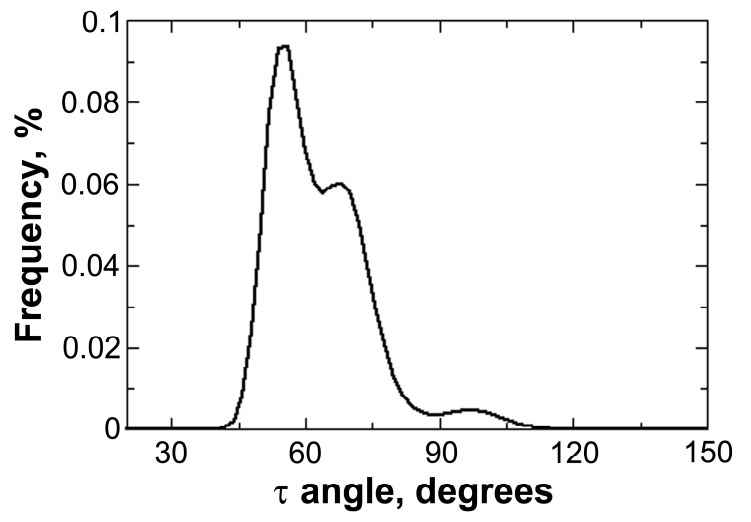

B

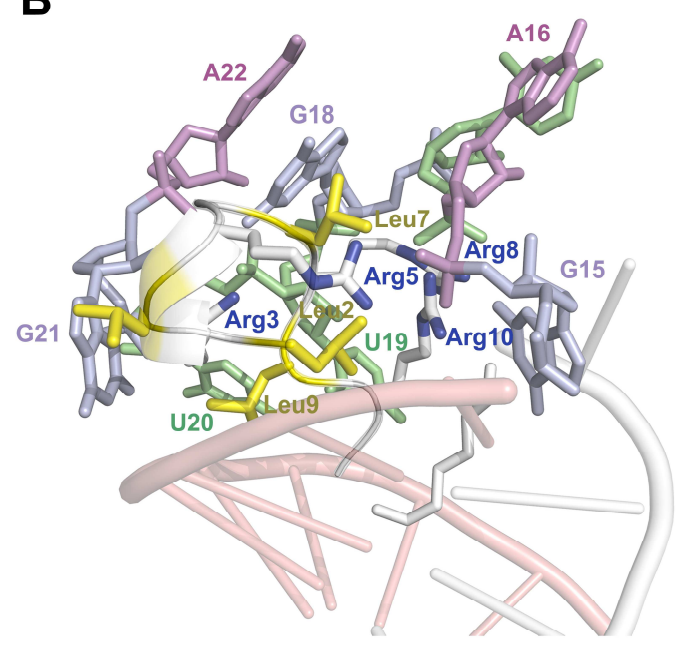

D

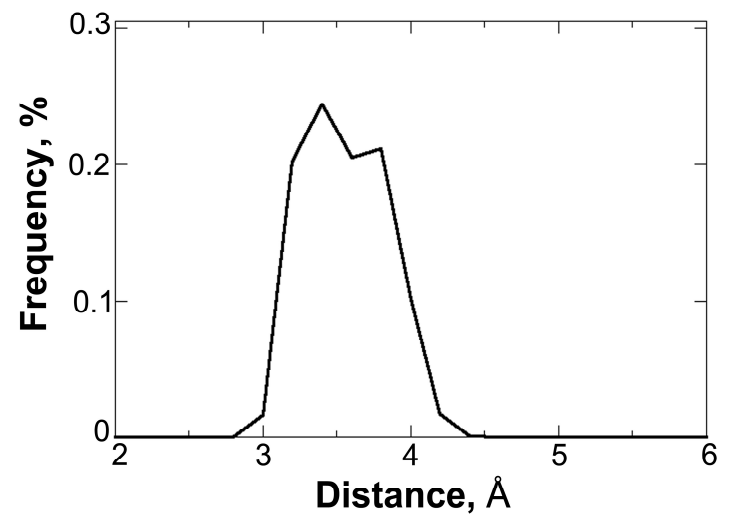



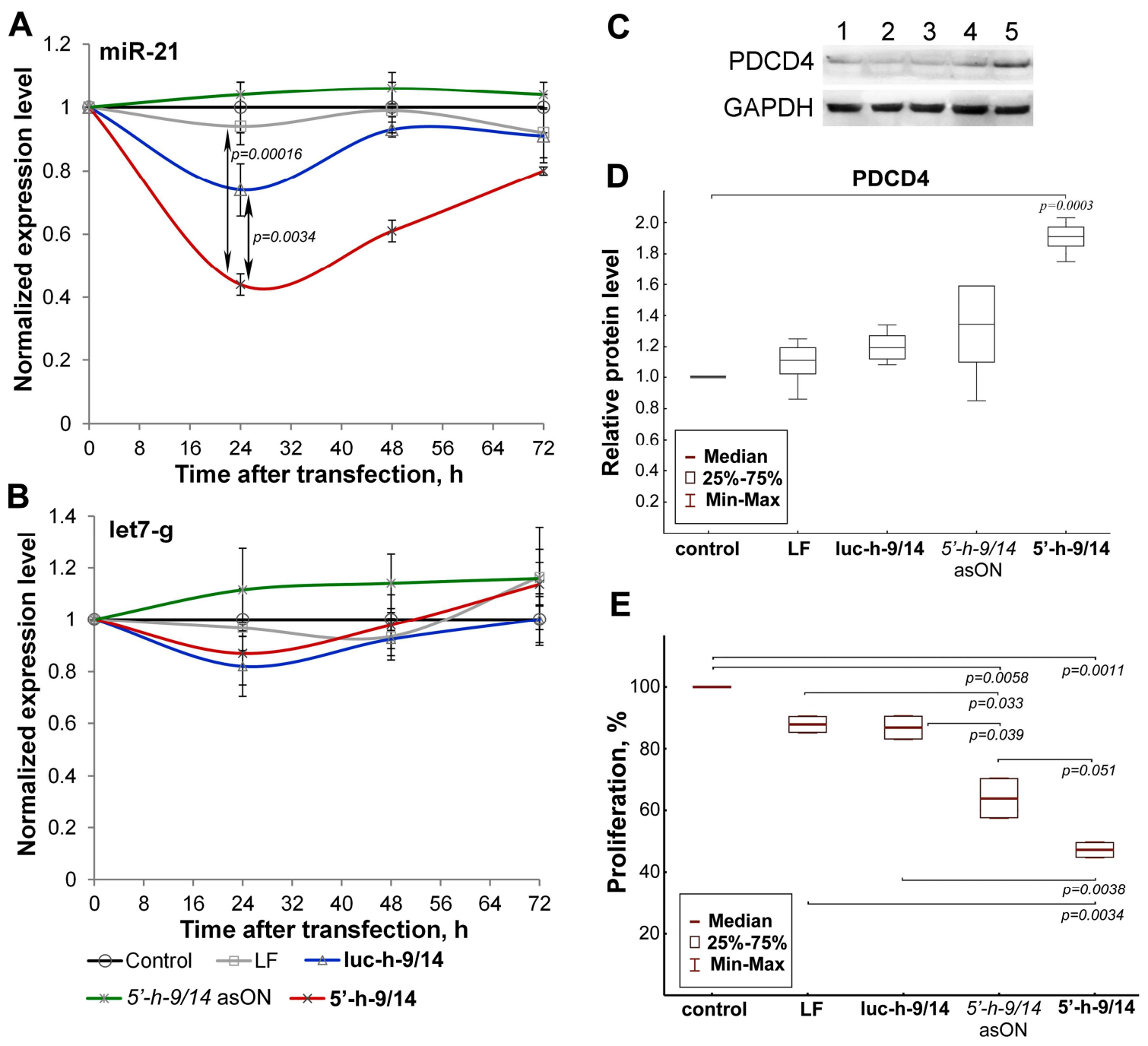